\section{Arquitecturas de barro y madera prerromanas en el occidente de Asturias: el Castro de Pendia}

\section{Clay and timber pre-roman architectures in the occident of Asturias: the hillfort of Pendia}

Fernando Rodríguez del Cueto*

Universidad de Oviedo

\begin{abstract}
Resumen
El castro de Pendia es un recinto fortificado de modestas dimensiones situado en el occidente de Asturias, que fue excavado en 1941 por A. García y Bellido y J. Uría Ríu. El caserío exhumado mostró un panorama arquitectónico homogéneo, en el que predominaban las construcciones pétreas de planta circular o rectangular con las esquinas redondeadas. La aparición durante la campaña de excavación del año 2006 de un conjunto de fragmentos de barro en los que se aprecian improntas de madera, asociados a un horizonte de carbones datado en la II Edad del Hierro, dieron pie a un estudio de las arquitecturas perecederas en esta comarca cuyos primeros resultados se presentan en este trabajo. En él se aborda, además de la descripción de los hallazgos y su contexto estratigráfico, un repaso al estado actual del conocimiento de las construcciones en materiales perecederos en el Noroeste peninsular, así como los materiales y técnicas constructivas empleadas.
\end{abstract}

Palabras clave: Edad del Hierro, Barro con improntas, C-14, NW peninsular.

\begin{abstract}
The Pendia hillfort is a small fortified enclosure located in the West of Asturias. It was excavated in 1941 by A. García y Bellido and J. Uría Ríu. The excavated village revealed a uniform architectural layout, in which circular or rectangular stone structures with rounded corners predominated. During 2006 excavation, a collection of clay fragments with imprints of wood, which are associated with a carbon horizon dated to the Second Iron Age, gave rise to an architectural study of the perishable architecture of this region. The initial results of which are presented in this paper. In addition to providing a description of the findings and their stratigraphic context, this study reviews the materials and construction techniques employed.
\end{abstract}

Keywords: Iron Age, Imprints in Clay, C-14, NW peninsular.

*rodriguezcfernando@gmail.com

Becario predoctoral Universidad de Oviedo-Banco de Santander.
En un primer momento, levantaron paredes entrelazando pequeñas ramas con barro.

M.L. Vitruvio. Los diez libros de arquitectura

\section{INTRODUCCIÓN}

La aparición de un conjunto de fragmentos de barro con improntas de madera en las campañas de excavación realizadas en el castro de Pendia es lo que motiva la redacción de este trabajo, en el que se incluye una primera descripción de las piezas junto con unas valoraciones iniciales sobre su contexto estratigráfico y sobre la tradición constructiva en la que se inscriben. El Norte peninsular es un espacio donde no se han desarrollado estudios particulares de este tipo de restos ${ }^{1}$, al contrario de lo que ocurre en otros ambientes protohistóricos peninsulares. Varios factores permiten explicar esta situación: por un lado el temprano inicio de las investigaciones en otros territorios (como el Mediterráneo) y la importancia de la construcción con elementos perecederos en sus poblados protohistóricos, que permitió una pronta e intensa especialización de la investigación hacia campos específicos como el de la arquitectura. En el Norte peninsular este avance se ha hecho con otros ritmos historiográficos; a este factor, se le suma que estamos ante materiales constructivos que para su pervivencia hasta la actualidad necesitan de cierta relación con el fuego. Tampoco ayudó la intensa ocupación que se ha desarrollado en muchos poblados, hecho común a buena parte de los poblados protohistóricos, pero que en el caso asturiano se puede ver incrementado por el limitado espacio de ocupación intramuros de buena parte de los lugares. Todos estos acontecimientos permiten explicar la singularidad que en este espacio puede tener un limitado elenco de materiales como los que aquí presentamos, que se convierten en los primeros estudiados con detalle en Asturias.

\section{EL CASTRO DE PENDIA. RESUMEN DE LAS INVESTIGACIONES}

El lugar conocido como El Castro se encuentra situado en las inmediaciones del pueblo de Pendia, en el concejo de Boal y a escasa distancia del río Navia. El poblado fue construido sobre la parte terminal de la ladera de los

\footnotetext{
${ }^{1}$ El mapa que acompaña al texto fue confeccionado atendiendo a aspectos cronológicos (yacimientos con fases de la Edad del Hierro) y materiales (restos de arquitecturas perecederas de la E.H.), sean éstos fragmentos de barro con improntas o bien restos de estructuras de cimentación: hoyos, calzos, etcétera. Entendemos que cuando perviven restos de arquitecturas perecederas éstas pueden materializarse en cualquiera de esas dos evidencias, siendo siempre ambos elementos (cimentaciones o paredes) partes de un mismo tipo constructivo.
} 


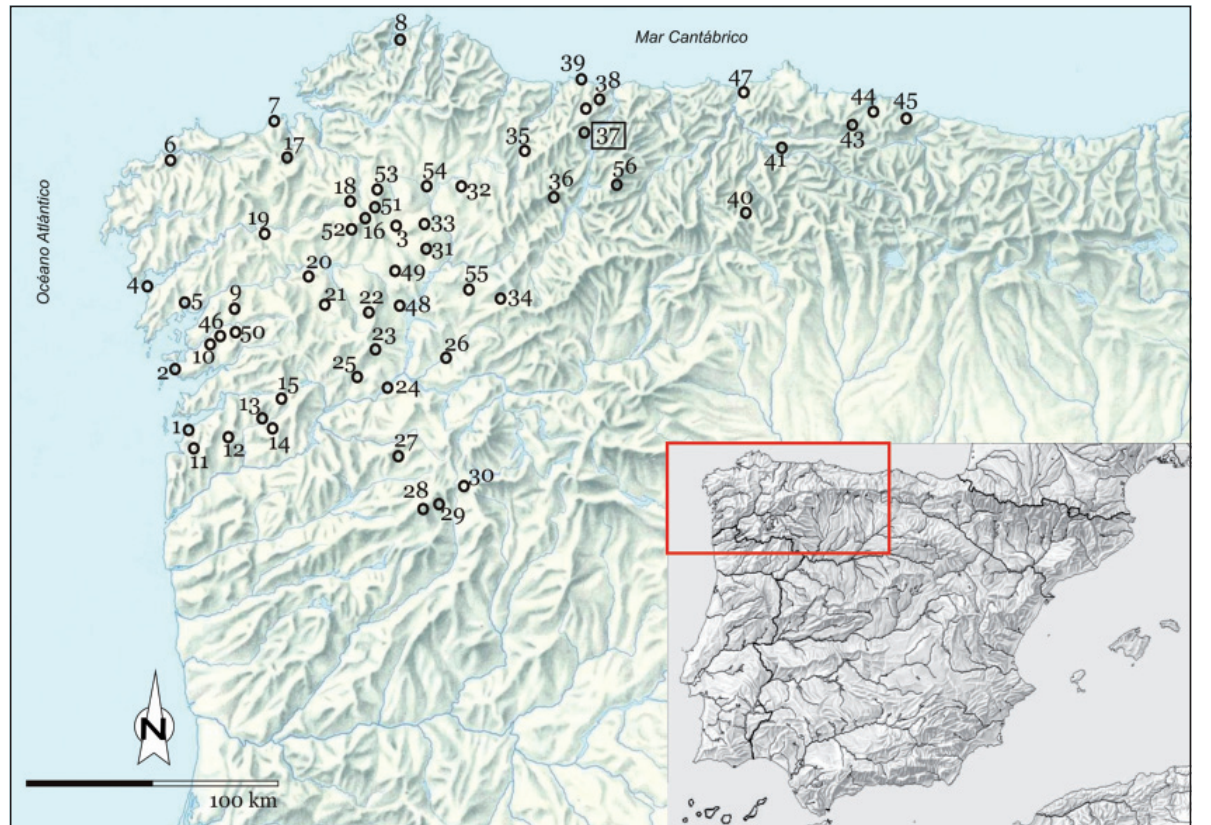

1-Toralla (Comunicación personal de Ángel Acuña a González Ruibal, 2006 2007: 197).

2-A Lanzada (Suarez y Fariña, 1990: 316)

3-Castro da Ourela (Álvarez Merayo, 2009: 59).

4-Baroña (Calo y Soeiro, 1986: 14).

5-Neixón Pequeno (Ayán y Franco, 2010:

47).

6-Borneiro (Lestón, según González

Ruibal, 2006-2007: 362).

7- Punta de Muros (Cano y Gómez,

2010: 255).

8-Castro do Tallo (Ramil González, 1989: 58).

9-Castrolandin (Ayán et alii, 2007).

10-San Tomé de Nogueira (López García

2008: 186).

11-Chandebrito (Lois Ladra, 2010: 36).
12-Torroso (De la Peña, 1992: 17-22). 13-Fozara (Hidalgo Cuñarro et alii, 1987: 21). 14-Troña (Hidalgo Cuñarro, 1984: 232).

15-Pena Redonda (González Ruibal, 2004: 56 ). 16-A Graña (Acuña y Meijide, 1991: 54; 1995: 23.

17-Castro das Travesas (Fernández Malde, 2008: 46)

8-Corredoiras (Rey, 1992: 103 según González Ruibal, 2006-2007: 360). 19-Cruceiro da Coruña (Parga Castro, 2008: 126).

20-Castrovite (Carballo Arceo, 1998, según González Ruibal, 2006-2007: 198).

21-Bendoiro (Fernández Pintos, 2008: 182).

22-Maceira (Carballo Arceo, 2002, según González Ruibal, 2006-2007: 360)

23-Coto do Mosteiro (Orero Grandal, 1988 : $35)$

24-Laias (Álvarez y López, 2000: 528).
25 Cameixa (López Cuevillas, 1953: 77) 26- Monforte (Álvarez Merayo, 2010: 64) 27-Castromao (García Rollán, 1971: 196) 28-Novás (Rodríguez Colmenero, 1976: 572 . 29-Saceda (Carreño Gascón, 1991: 61). 30-Outeiro da Ponte (Álvarez González, 1996, según González Ruibal, 2006-2007: 371). 31-Castromaior (López González, 2008: 34). 32-Viladonga (Arias Vilas, 1991: 74; 1995: 2628 y Tomás Botella, 2008: 39).

33- Penarrubia (Arias Vilas, 1979: 615)

34-Castro da Moura (Rodríguez García, 1991, 1992 según González Ruibal, 2006-2007: 367).

35-Taramundi (Villa Valdés et alii, 2007: 273) 36- Chao Samartín (Villa Valdés, 2007b: 29). 37-Pendia (Rodríguez y Villa, 2009: 165).

38-Coaña (Maya, 1988: 27).

39-Cabo Blanco (Fanjul Mosteirín et alii, 2009: 262). ig. 1. Mapa con los yacimientos de la Edad del Hierro de Galicia y de Asturias con restos de arquitecturas perecederas, así como otros lugares mencionados en el ento. En un recuadro, el castro de Pendia (Mapa elaborado por el autor a partir de cartografía escargada del Instituto Geográfico Nacional()
Montes de Villanueva, que forma parte de la Sierra de Penácaros. Buena parte de este espolón se encuentra rodeado por el arroyo de Pendia que forma un pequeño meandro en su curso hacia el Navia. La elección del emplazamiento combina la existencia en el entorno inmediato de los recursos necesarios para la subsistencia con una localización que, a pesar de su baja cota en el valle y su depresión sobre buena parte del entorno, permite una fácil defensa de la plaza. La escasa altitud en el valle del recinto ya llamó la atención de investigadores como J. L. Maya, que destacaba la poca insolación del lugar o la abundante humedad que presenta el sitio (Maya, 1988: 41), junto con una desproporción evidente entre sus fortificaciones y la escasa superficie habitable. El castro de Illaso, situado en el concejo de Illano y a poca distancia de Pendia² (Jordá, 1964: 370; Maya, 1988: 36), o el castro de Lineras en Santa Eulalia de Oscos (Villa, 2004: 90-91),

${ }^{2}$ La separación entre ambos yacimientos es de unos cuatro kilómetros en línea de aire. son los dos castros del occidente asturiano que quizá presenten mayores similitudes en cuanto a su emplazamiento con Pendia 3 .

Las primeras descripciones del castro de las que tenemos noticia las proporciona B. Acevedo y Huelves a finales del siglo XIX, textos que serán incluidos en el libro de Boal y su concejo y posteriormente en la obra Asturias (Bellmunt y Canella 1900: 191). A finales de los años veinte del siglo pasado y durante los primeros años de la década de los treinta se suceden alusiones escritas al sitio, junto con las primeras excavaciones de las que tenemos constancia. En cuanto a las descripciones, A. García Martínez incluye Pendia en su inventario de lugares prehistóricos escrito en $1929^{4}$. Las primeras excavaciones ocurrieron en 1934, cuando un vecino de Boal exhuma

${ }^{3}$ Fuera del ámbito del occidente asturiano algunos recintos del Caurel, como el Castro do Vilar, presentan características muy semejantes en cuanto a emplazamiento y modelos constructivos (Luzón y Sánchez Palencia, 1980: 22).

${ }^{4}$ Prehistoria del occidente de Asturias. Inédito. 
algunos restos en la zona norte del poblado. Sus materiales serán recuperados por la Comisión de Monumentos para luego pasar a la colección del Museo Arqueológico de Asturias. Desde los años 1939-40 A. García y Bellido y J. Uría se encuentran vinculados al castro de Coaña y la excavación de Pendia pudo venir incitada por esas primeras noticias de B. Acevedo y Huelves, así como por el deseo de explorar lugares próximos a Coaña. La excavación de este pequeño poblado se realiza en 1941, trabajos que se publicaron al año siguiente (García y Bellido, 1942) lo que produjo, gracias a la fama de sus investigadores y a su pronta divulgación a nivel nacional, que se convirtiera en un referente muy mencionado en la bibliografía (Fernández y Villa, 2004: 133).

Estas excavaciones de distinta índole que se suceden entre las décadas de los treinta y los cuarenta del siglo XX dejan a la vista la mayor parte del caserío que se conoce actualmente de Pendia. Al interior, poco más podemos añadir a la ya bien descrita separación en dos recintos diferenciados separados por una estructura defensiva (Romero, 1976: 107; Carrocera et alii, 1986-87: 223; Maya, 1988: 41). Es en el extremo meridional del poblado donde se agrupan la gran mayoría de las construcciones que vemos en la actualidad: las 13 construcciones excavadas por A. García y Bellido, junto a dos saunas castreñas. Excavaciones más recientes del espacio inmediato a la sauna 2 propiciaron el hallazgo de una nueva construcción. A esto habría que unir los restos de nuevas estructuras que afloran en superficie, en zonas que no fueron excavadas en 1941.

Durante los años ochenta se llevan a cabo una serie de limpiezas y de adecuaciones del recinto bajo la dirección de E. Carrocera, a la par que se intenta proteger los dos edificios de baños; durante estas actuaciones no se realiza ningún tipo de excavación (Carrocera, 1990: 158).

Ya bajo la dirección de A. Villa Valdés y desde el año 1999 el proyecto cobra un nuevo impulso: las saunas castreñas son reexcavadas y consolidadas, ya que por aquellos momentos se estaba preparando una relectura de este tipo de edificios en todo el valle (Villa, 2000). Sobre esa base y desde el año 2003 se inicia un programa de actuación inspirado en los parámetros del Plan director de la Cuenca del Navia (Villa, 1999), con el objetivo de sanear el mayor número posible de espacios del poblado. Actuando sobre lugares ya excavados, así como sobre puntos concretos del poblado que aún se encontraban intactos. Las excavaciones se desarrollaron durante breves campañas estivales que recibieron un apoyo administrativo constante, siempre dentro de unos parámetros de personal

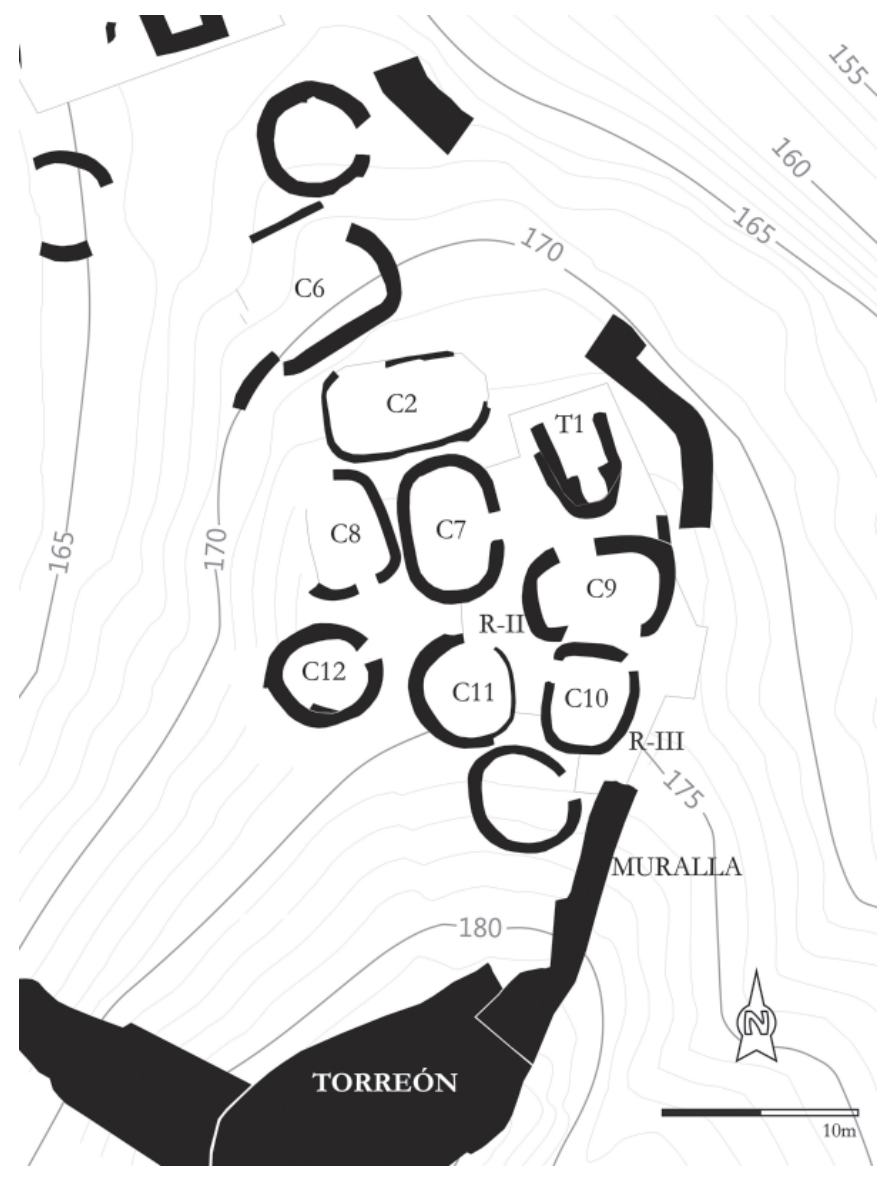

Fig. 2. Plano de detalle del caserío Sur del Castro de Pendia, con indicación de las zonas excavadas. (Plano base de Esperanza Martín: PANE- Consejería de Cultura y Turismo del Principado de Asturias)

acordes a la propia capacidad del concejo. Se trataba de cumplir anualmente propósitos muy concretos: definir un espacio, recuperar toda la información disponible en el mismo y proceder a la restauración de aquellas zonas más afectadas. Esto permite la excavación y consolidación de C-2, C-7, C-8, C-12, C-9, C-10 y C-11 y C-6/ C-3, así como de una serie de espacios en el entorno inmediato de construcciones (C-12 exterior), o de lugares de paso y comunicación dentro del poblado como R-II y R-III (Figura 2). Mientras que la excavación de las saunas fue publicada en varias síntesis acerca de estos edificios (la más reciente, Villa, 2007), el resto de trabajos cuenta con una primera descripción de reciente publicación (Rodríguez y Villa, 2009).

\section{GEOLOGÍA Y MATERIAS PRIMAS}

El castro se encuentra situado en el terreno de las Pizarras de Luarca, dentro de la denominada zona astur-occidental leonesa, en el dominio del Navia y alto Sil. En este sector se localizan según A. Marcos Vallaure: «niveles de nódulos 
arcillosos, delgadas capas de hierros oolíticos y algún banco de areniscas o cuarcitas. [...] facies de pizarras negras con poco material elástico, presencia de materia orgánica y sulfuro de hierro, ausencia de carbonatos [...]» (1973: 30). Estas características geológicas son las que justifican la presencia de grandes bolsadas de arcillas de color rojizo. En algunos taludes próximos al castro aún se reconoce la entidad de estos paquetes de arcillas, que seguramente fueron aprovechadas en algún momento tanto para construir las casas de piedra, como para emplearla como revoco de las construcciones en materiales perecederos. En el ámbito cercano al castro se reconocen actualmente varios lugares en los que se extrajo barro el siglo pasado. En concreto, hemos podido recopilar testimonios de que hace unos sesenta años la gente de $C a^{\prime} X u a n$ d'Arriba (o el Canigón), situada en las proximidades del castro, extrajo barro para la construcción de un horno a unos 330 metros en línea de aire ${ }^{5}$ del poblado. Lugares conocidos como As barreiras o Barreiros se localizan a 700 metros y a un kilómetro y medio respectivamente de Pendia.

Otros topónimos que en principio pueden pasar desapercibidos como $A$ viña de arriba y $A$ viña de abaixo, a una distancia de 350 metros del castro también nos pueden resultar ilustrativos acerca de la abundancia de arcillas en el lugar. Los suelos arcillosos son muy adecuados para la vid (Collantes, 1855: 288-289, t. VII) y la presencia de muchas referencias toponímicas en el entorno vinculadas a viñedos ${ }^{6}$, es otro síntoma de la proliferación de unos suelos que son parte importante en el desarrollo de este tipo de cultivos. En buena parte de esos cortes próximos al poblado también se pueden apreciar inclusiones muy diversas y de diferentes tamaños en las arcillas. Los elementos que más abundan son los esquistos, que también estarán muy presentes en el barro prehistórico tal y como veremos a continuación.

\section{LA IMPORTANCIA DEL CONTEXTO. CONDICIONANTES EN LA INVESTIGACIÓN DE LA ARQUITECTURA DE TIERRA Y MADERA}

La cuestión fundamental que creemos que se debe analizar en primer lugar, es la del lugar de la excavación en el que están apareciendo esos restos así como su contexto estratigráfico. En el caso de Pendia las muestras de barro fueron halladas en distintos espacios del poblado, aunque podemos fijar dos focos principales en los que se acumulaban

${ }^{5}$ En este apartado, todas las distancias se referirán a mediciones en línea de aire desde el centro aproximado del castro.

${ }^{6}$ Muy cerca de Pendia también tenemos el núcleo de As Viñas.

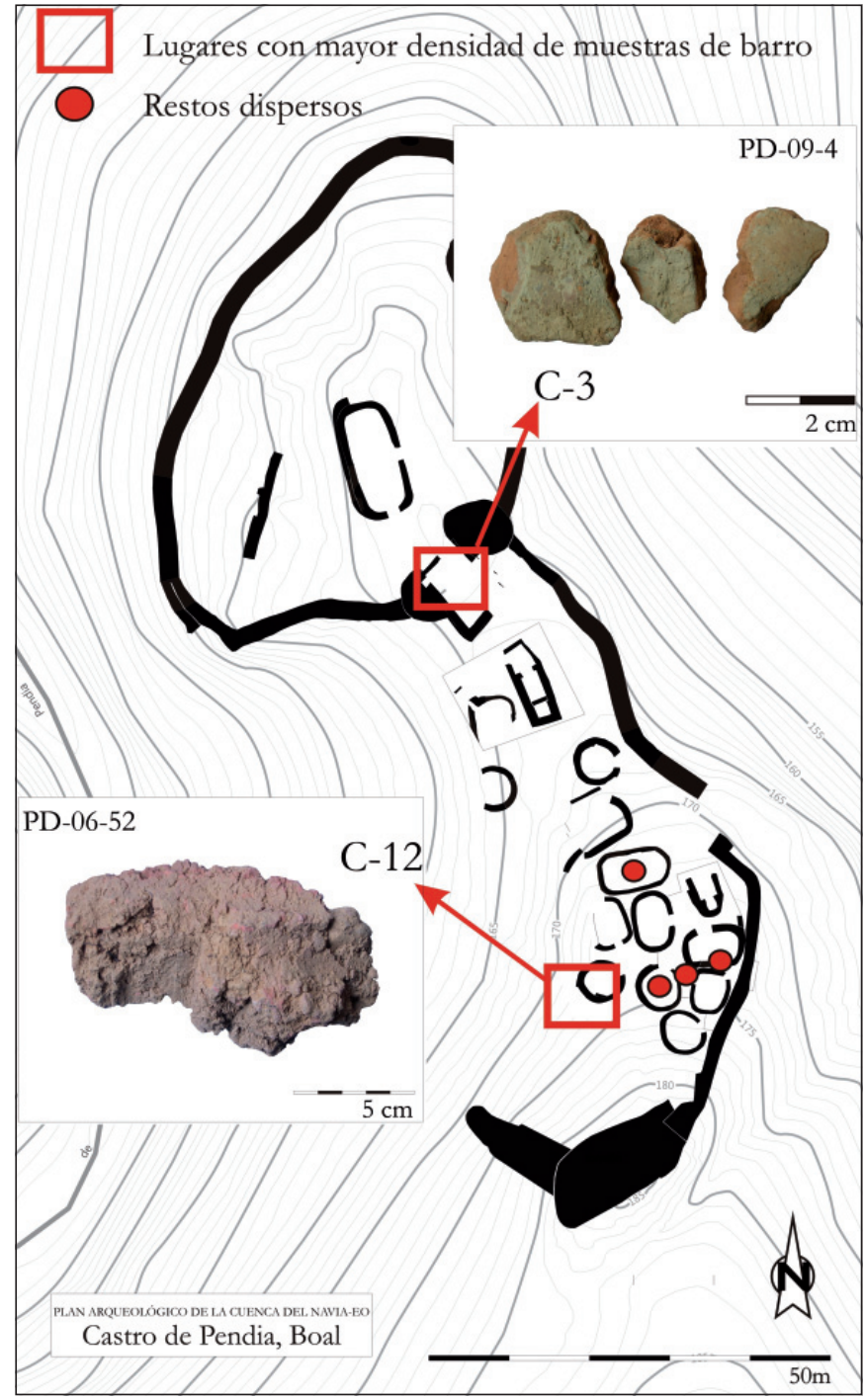

Fig. 3. Plano del yacimiento de Pendia, con las localizaciones de los hallazgos de revocos de barro. (Plano base de Esperanza Martín: PANE- Consejería de Cultura y Turismo del Principado de Asturias)

un número muy significativo de restos; es el caso de los sectores C-3 y C-12 (Figura 3). El primero de ellos no será tratado con mucho detenimiento, pues es una zona que merece un análisis particular y se encuentra aún en proceso de investigación.

En el caso de C-12 nos enfrentábamos a una construcción que fue excavada por A. García y Bellido y ante la cual el investigador prestó un especial interés (1942: 295), dándole gran repercusión a nivel científico en base a un dibujo de detalle de las estructuras exhumadas que luego fue incluido en otros trabajos (García y Bellido, 1942b: 228, Maluquer, 1963: 53).

La excavación de 1941 se detuvo a una cota que podemos relacionar con los niveles de época romana de 
esta construcción, pero por debajo de estos horizontes aún quedaban ocupaciones más antiguas. Además, también se pudo excavar una zona anexa a la cabaña (denominada C12 exterior), en el pasillo que mediaba entre el muro oeste de ésta y la ladera occidental del poblado. Este espacio, de apenas unos 20 metros cuadrados, fue excavado mediante un sondeo de $6,30 \mathrm{~m}$ por $2,80 \mathrm{~m}$, que deparó una secuencia prácticamente intacta ${ }^{7}$ en la que se acumulaban varias fases constructivas colmatadas por los derrumbes del torreón meridional.

El contexto remitía en todo momento a elementos más antiguos que $\mathrm{C}-12$, que luego fueron muy remozados para la erección de esta construcción, modificando buena parte del espacio. La posición estratigráfica de los restos de barro demuestra que los muros de C-12 son posteriores a los depósitos en los que aparecen los revocos estudiados. En el interior de la construcción 12, pero ya en los últimos horizontes antes de la aparición de la roca, también aparecieron los restos de un conjunto de lajas de pizarra. Esos restos fueron considerados restos de posibles pavimentos dada su similitud con otros documentados en la comarca. El estudio detenido y la aparición de este tipo de estructuras en diversos castros del NW asociados a estructuras arquitectónicas, nos lleva a ponerlos en relación con restos de cimentaciones de construcciones perecederas. Las lajas de pizarra de tamaño mediano aparecen hincadas en el suelo, formando en muchos puntos una triple hilera de cuñas que sigue una disposición regular y de corto recorrido, que no permite precisar excesivamente acerca de la planta de la posible construcción. La tendencia de las piedras parece remitir a una forma arqueada. Los fragmentos de barro aparecen en el entorno de estas lajas hincadas, tal y como se puede apreciar en la figura 4 . Al exterior de la cabaña el pasillo que hemos excavado en el sondeo C-12 exterior quizá fuese un producto intencionado para ganar altura y contar con una superficie regular que facilitase el acomodo de la cabaña, evitando que ésta pisase hacia la ladera, creando a su vez una superficie en su entorno por la que se puede circular (aunque también se podría utilizar para otros fines comunes o particulares); todo ello siempre durante la última fase de uso de este espacio. En el extremo sur del sondeo la secuencia constructiva, con varios muros superpuestos en cuyo entorno se localizó la contera de un puñal de antenas (Rodriguez y Villa, 2009: 168), también demostró el sucesivo interés en construir en la zona de la ladera en momentos más antiguos que C-12. Debido a la

${ }^{7}$ Una trinchera separaba parte del tramo norte del sondeo de la construcción C12. De todos modos, las estructuras recuperadas en nuestro sondeo se pueden considerar, en su gran mayoría, anteriores a esta edificación. escasa superficie excavada, no se puede precisar más acerca de la finalidad de estos muros.

El estrato en el que se concentraban buena parte de las muestras localizadas en este sector era una capa de tierra de color rojizo con una potencia estratigráfica de unos 25 centímetros, diferenciada como unidad 91 (Figura 4). Se extendía por buena parte del tramo norte del sondeo y en ella abundaban los restos de barro cocido, así como restos de maderas quemadas de sección circular que aparecían a modo de pequeños tacos.

Por debajo de esta unidad, una lengua muy fina de carbones (unidad 107), permitió el muestreo por $\mathrm{C}^{14}$ con un resultado de 340-320 cal. A.C. y $210 \mathrm{cal}$. a.C.-10 cal. D.C. $\left(95 \%\right.$ calibración a dos sigmas) ${ }^{8}$. Esta datación fue la primera referencia de cronología absoluta que en su momento permitió sospechar un origen prerromano en el poblado", suposición que quedó confirmada en los sondeos parciales del encintado defensivo que proporcionaron varias fechas cuyas horquillas de calibración convergen en distintos momentos de la II Edad del Hierro (Rodríguez y Villa, 2009: 169).

El contexto general de las muestras es, por tanto, el del derrumbe de estructuras de materiales perecederos que, vista la asociación entre revocos y madera quemada y las características de la capa en la que se han recogido un mayor número de barros (una capa gruesa y homogénea), no debió producirse muy lejos de este espacio. Aunque hemos de considerar la posibilidad de que el derrumbe se haya producido de un modo controlado a través de distintos medios ${ }^{10}$, y luego el material constructivo volcado en este lugar ${ }^{11}$, más bien parece que la ubicación cercana de una cabaña de materiales perecederos justificaría la homogeneidad y potencia de las capas y la superposición ordenada de los elementos ${ }^{12}$, que no parecen consecuencia de un arrastre sucesivo por el suelo (o de un acarreo) desde zonas más alejadas, lo que removería más los distintos componentes del derrumbe y acabaría produciendo un estrato mucho más diverso en su composición. Parecen por tanto los únicos restos que han pervivido en el entorno

\footnotetext{
${ }^{8}$ BETA-231044.

${ }^{9}$ Ya considerado hace tiempo por algunos autores, en vista de la antigüedad de ciertos materiales recuperados en el yacimiento (Maya, 1988: 41). Varias dataciones de radiocarbono posteriores en el caserío sur de Pendia confirmaron la existencia de fases de la II Edad del Hierro (Rodríguez yVilla, 2009: 169).

${ }^{10}$ Procesos que pudieron suponer un desplome intencional y controlado de las paredes, para luego trasladar los escombros hacia este espacio en elementos menores con la ayuda de cestas o similares.

${ }^{11}$ Como parece que ocurre en Fozara (Hidalgo et alii, 1987: 21) o en otros yacimientos de la Edad del Hierro peninsular (Celis, 1993: 101).

${ }^{12}$ Secuencia que parece semejante a las que describe J. Camino para algunos derrumbes de este tipo de construcciones en la ría de Villaviciosa (1997: 65).
} 
(A)

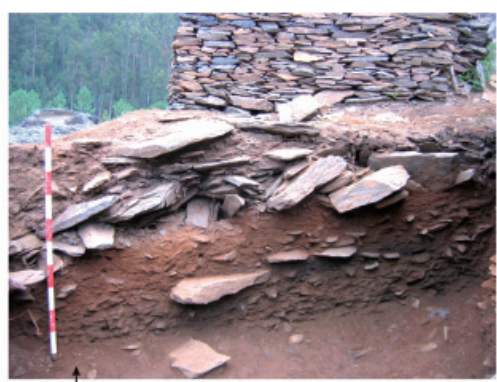

(C)

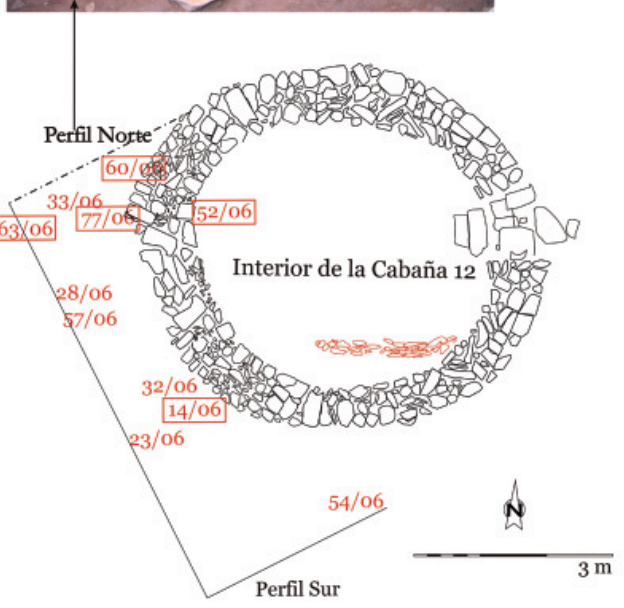

(D)
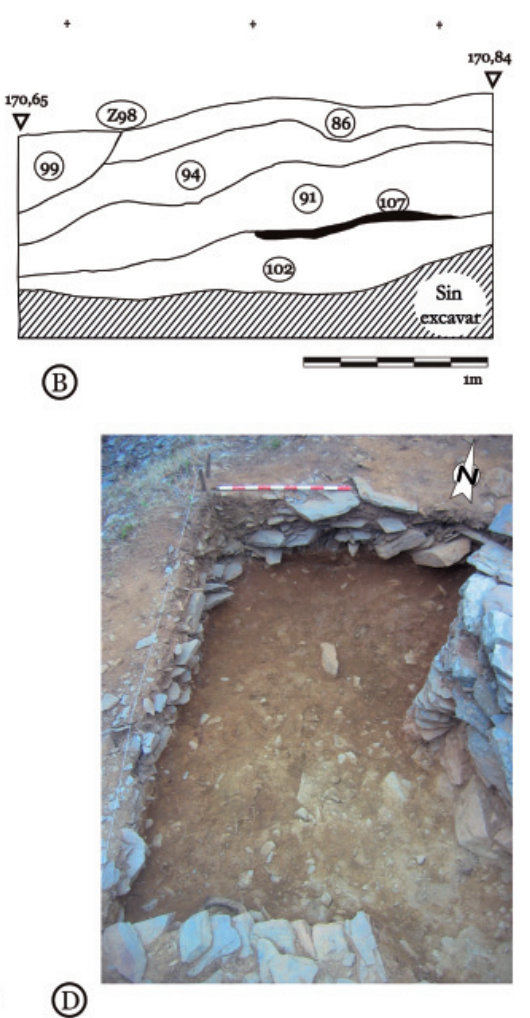

Fig. 4. A. Fotografía del perfil norte de C-12 exterior. B. Dibujo del perfil norte de $\mathrm{C}-12$ exterior con indicación de las unidades estratigráficas. C. Localización en planta de los restos en la cabaña C-12 y el sondeo C-12 exterior. En un cuadro las muestras estudiadas en este artículo. En rojo en el interior de C-12 se indican los restos de cimentaciones. D. Vista en planta de la unidad 91 de los derrumbes de una cabaña construida en materiales perecederos. Los desplomes de la cabaña quizá quedaron intactos por encontrarse al borde de ladera, en un lugar en el que esos derrumbes no molestan; al contrario, ayudan a dar firmeza y regularidad al terreno, permitiendo a su vez ganar cota. Sin embargo, en otras zonas muy próximas, como el interior de C-12 las obras posteriores pudieron

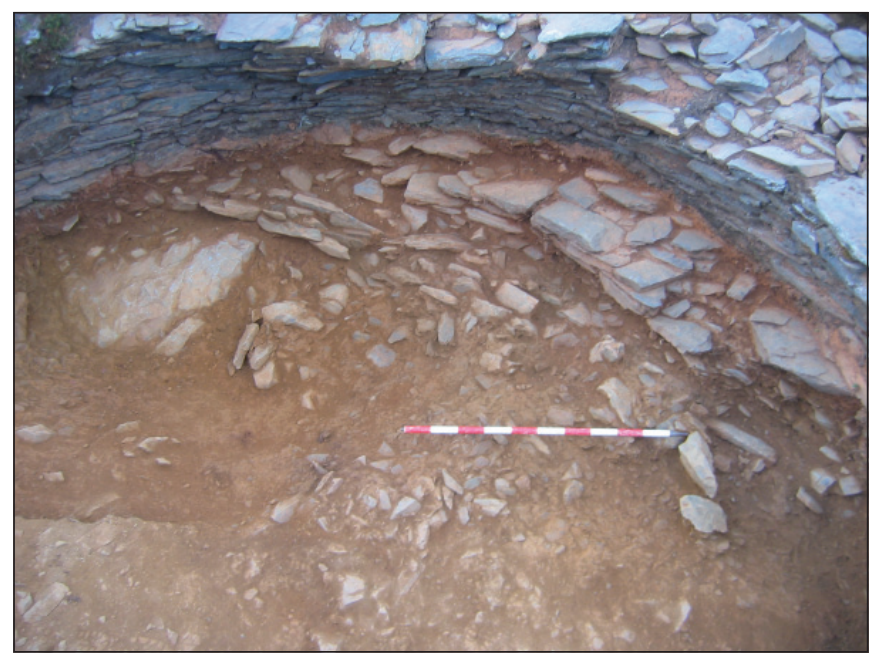

Fig. 5. Fotografía de los restos de posibles cimentaciones, por debajo de los muros de C-12 y de un muro anterior a ésta, que pudo servir de banco de la cabaña tal y como ya interpretó García y Bellido. Las lajas se encontraban clavadas en superficies muy próximas a la roca alterar más esas secuencias haciendo desaparecer buena parte del derrumbe original. Si ese conjunto de lajas hincadas se corresponde, como parece, con cimentaciones las reformas posteriores habrían hecho desaparecer las que aún pervivieran in situ (Figura 5).

Los restos constructivos por su relación con el fuego, han podido pervivir entre la tierra y permiten a su vez datar la madera proporcionándonos una fecha para este tipo de arquitecturas. Es probable que muchos otros elementos se hayan deshecho en la capa 91, lo que explicaría la potencia y el color de esta tierra, producto de la disolución de todos los restos de manteado que no se hubieran endurecido lo suficiente a causa del incendio.

$\mathrm{El}$ resto de fragmentos de barro recuperados, aparecen ya de un modo aislado sin que se identifiquen grandes agrupaciones de revocos. Se pueden clasificar en dos tipos de contextos muy bien diferenciados. El primer tipo estaría integrado por aquellos barros hallados en niveles situados entre los últimos horizontes ${ }^{13}$ de ocupación de las construcciones y la roca natural: es el caso de C-11 o de C-6. Dentro del segundo tipo tendríamos aquellos revocos recuperados dentro de rellenos de tierra mezclada con piedras que, o bien permitieron la creación de terrazas

${ }^{13}$ Hablamos de los últimos horizontes en términos estratigráficos, no temporales, lo que los convierte en los niveles de ocupación más antiguos de estas construcciones. 
sobre las que construir nuevas cabañas, o bien posibilitaron alzar el nivel de antiguas zonas comunes adaptándolas a las nuevas necesidades del poblado. Como ejemplo del primer caso: el relleno localizado entre los edificios C-9 y C-10, que creó la terraza sobre la que se construyó esta última construcción (Rodríguez y Villa, 2009: 163). Mientras que el relleno que alza la cota de la calle R-II (Figura 2) nos podría servir de ejemplo del segundo caso. En todos los ejemplos estudiados, las superficies en las que se han recuperado los materiales no se vieron afectadas por las excavaciones previas del lugar.

Aunque la muestra datada de madera presenta una calibración bastante amplia, si unimos esta referencia absoluta al contexto estratigráfico, le sumamos la similitud de las muestras con otros restos constructivos de la Edad del Hierro, así como la presencia de posibles estructuras de cimentación muy semejantes a las ya documentadas para estos períodos, es lógico pensar que los restos arquitectónicos incluidos en este trabajos estuvieron vigentes en el poblado en algún momento de la II Edad del Hierro.

\section{MUESTRAS DE BARRO ESTUDIADAS}

El conjunto recuperado en las campañas de excavación desde el año 2003 está formado por unos cien fragmentos de barro de distintas características. Dentro de este grupo de muestras nos encontramos desde trozos de pequeño tamaño (PD-06/107: $19 \times 22 \times 12 \mathrm{~mm}$ ), hasta otros de cierto porte (PD-06/14: $129 \times 35 \times 28 \mathrm{~mm}$ ). Es en los individuos de mayor tamaño y grosor en los que se reconocen las huellas de las estructuras de madera que se encontraban recubriendo en su momento, si bien se puede asegurar que todos ellos estuvieron en contacto con el fuego, fenómeno que facilitó la conservación de las muestras al evitar su disgregación y disolución.

La morfología de los barros es muy diversa, identificándose desde pellas de barro totalmente irregulares, a ejemplos que presentan muy bien definida una superficie externa que fue la que estuvo a la vista en el momento de uso. Algunos incluso conservan restos de varias capas de enlucido de color blanquecino, principalmente los recuperados en el entorno de los sectores C-12 y C-3 (Figura 3). También podríamos destacar varias piezas que cuentan con restos de color azul en sus superficies exteriores. Sólo el análisis y estudio mineralógico de estas superficies podrá determinar la naturaleza de esta película azulada, pero la geología del lugar no suele producir este tipo de colores en las arcillas locales, caracterizadas más bien por su relación con el hierro que les da su tono rojizo. Como tampoco se han documentado procesos post-deposicionales que puedan explicar estas manchas y, a falta de más estudios o de la aparición de nuevos elementos de mayor tamaño, de momento hay que pensar en que podamos estar ante una capa protectora o decorativa (o ambas cosas), aplicada ex profeso.

Si bien buena parte de estos cien fragmentos de barro son de pequeño tamaño y no tienen relación con las estructuras que estaban revistiendo, no ocurre así con las pellas que cuentan con restos de improntas, ya que nos remiten a armazones de madera que son muy frecuentes en los poblados fortificados del Noroeste de la Península.

Se ha venido considerando en todo momento que estos revocos estaban revistiendo arquitecturas de carácter doméstico, ya que si bien no se puede descartar por completo, no se han localizado aún restos de revestimientos de barro asociados a estructuras defensivas, fenómeno que sí se conoce en otros poblados protohistóricos peninsulares. Los poblados ibéricos, por ejemplo, sí que presentan estos revestimientos en las fortificaciones, las cuales podían incluso ir encaladas (Chapa y Mayoral, 2007: 104; Bonet, 2006: 27); en La Bastida de Alcuses también se han recuperado restos de improntas de madera de sección semicircular o redondeada vinculados a las fortificaciones (op. cit.: 28). Sin embargo, en buena parte de los modelos establecidos para las arquitecturas defensivas centroeuropeas en las que se utiliza el entretejido de varas de madera a modo de paramento externo, no se incluye el revestimiento con barro de esos paños exteriores (Audouze y Buchsenschutz, 1989:112 y 115; Fichtl, 2005: 48). Quizá los análisis de estas arquitecturas de madera en Centroeuropa estén condicionados en primer lugar por el afán en comprender el funcionamiento estructural de estas fortificaciones. Cuestión que resulta comprensible viendo la diversidad constructiva que presentan las defensas y su complejidad, lo que le concede prioridad a este aspecto del análisis frente a otros detalles de la fortificación. Por otro lado, quizá no se le pueda pedir más a los restos constructivos, que al estar formados por materiales perecederos son más difíciles de documentar tras su ruina. La conservación es mucho mejor si las defensas han sido realizadas en piedra en alguno de sus puntos (Audouze y Buchsenschutz, 1989: 116), y también ayuda a que la reconstrucción sea más completa. La carencia de revestimientos asociados a las estructuras defensivas puede resultar por tanto atípica si pensamos sólo en términos de conservación del material constructivo, ya que el revestimiento siempre ayuda a paliar el efecto del agua y el sol sobre la madera, alargando la vida de ésta ${ }^{14}$.

\footnotetext{
${ }^{14}$ Las estructuras vegetales sin revestimiento de barro realizadas por Reynolds para evaluar el tiempo que pueden durar la madera desprotegida, deparó que se
} 


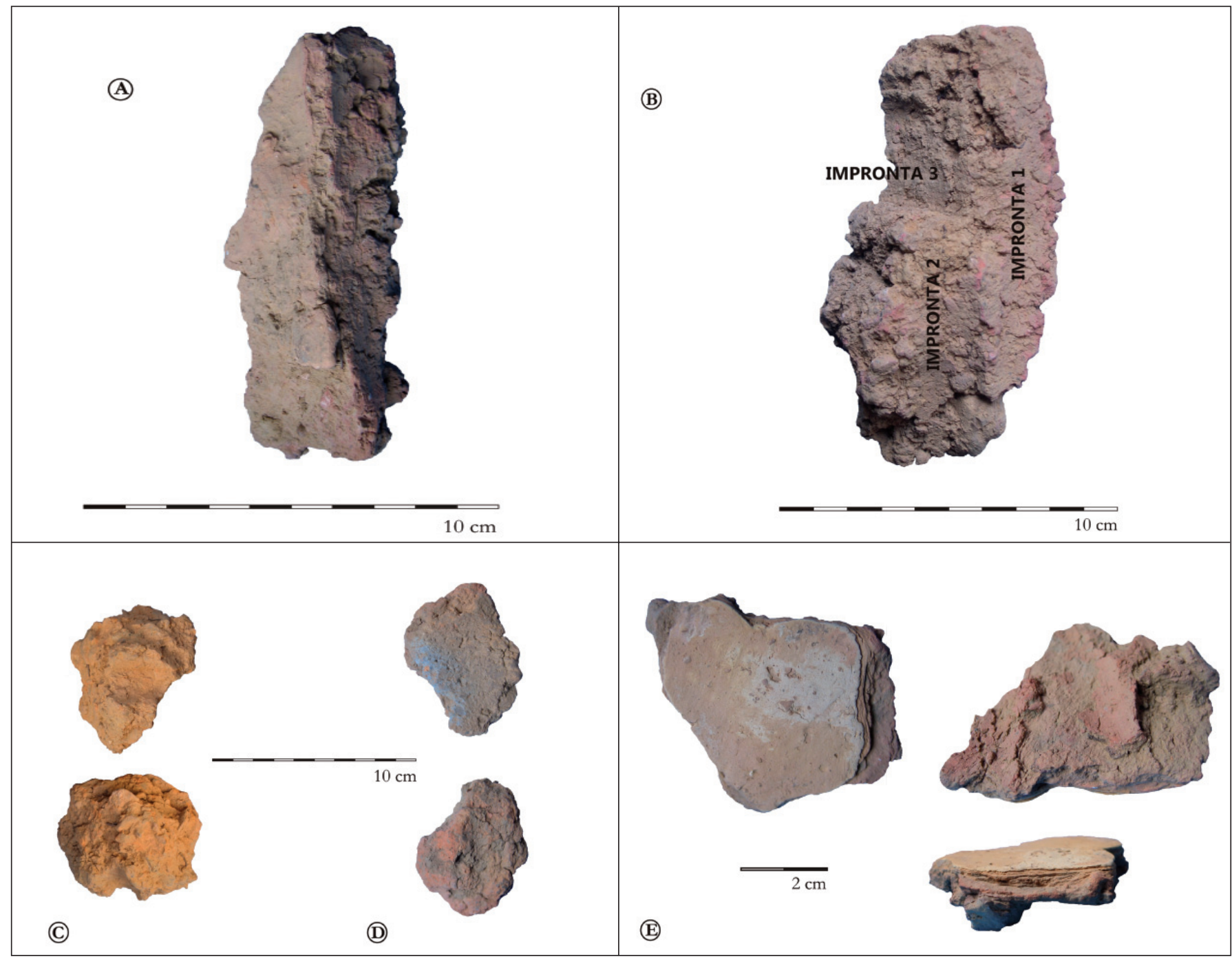

Fig. 6. Fragmentos de revocos localizados en el castro de Pendia. A. PD-06/ 14. B. PD-06/52 (parte posterior). C. PD-06/60 (parte posterior y fotografía cenital). D. PD-06/63 (cara vista arriba y parte posterior abajo). E. PD-06/77 (cara vista, parte posterior y sección de la pieza)

Pero no hay que olvidar que durante la Edad del Hierro, al menos en el caso asturiano, las estructuras defensivas se levantan principalmente en piedra, lo que también nos debe hacer pensar en el desarrollo que pudieron tener los elementos perecederos en las fortificaciones o sobre las condiciones de su ruina y desaparición En Asturias únicamente se han documentado en algunos castros orientales (Camino, 1995: 120) ${ }^{15}$. Quizá sólo la

vuelve quebradiza a los cuatro años (1988:36). Los entramados de madera también resisten mucho menos que otro tipo de construcciones realizadas en tierra que sí que pueden permanecer sin revestimiento (Vela, 2005: 157).

${ }^{15}$ Tanto en Asturias como en los modelos centroeuropeos también es posible encontrar estructuras mixtas, de piedra en la zona inferior y remate con empalizada perecedera.

16 Únicamente habría que reseñar la aparición de fragmentos de barro asociados a la cubierta en el castro de Zoñán, si bien éstos estarían vinculados a construcciones hechas en piedra de época romana (Vigo, 2006: 69). continuación de las excavaciones y la aparición de nuevos elementos bien contextualizados podrán resolver en un futuro esta cuestión.

Partiendo por tanto de la premisa de que son restos propios de las arquitecturas domésticas, tal y como parecen sugerir el contexto y los elementos asociados, la siguiente cuestión que debemos plantearnos es a qué parte de las construcciones pertenecen. En función del modelo hipotético de cubierta que se ha supuesto en la Edad del Hierro de los castros del Noroeste, lo más lógico es pensar siempre que estamos ante restos de paredes, debido a que las techumbres hechas en materiales vegetales no precisan de recubrimientos de barro tal y como demuestran los ejemplos etnográficos que más se aproximan a ese modelo ${ }^{16}$. El recubrimiento con barro sí se utiliza en otros yacimientos peninsulares en los que los tejados presentan morfologías 
muy distintas. Es el caso de los cañizos revestidos con barro utilizados para las cubiertas planas de la protohistoria levantina (Belarte, 1999-2000: 87; Morer et alii, 2000: 381), o de los techos de las construcciones meseteñas levantadas en adobes (Heredero, 1995: 286).

El contexto en el que se han localizado las muestras descarta que nos encontremos ante los restos de tabiques divisorios de las cabañas actuales, ya que en todos los ejemplos documentados en el poblado los restos se encuentran por debajo de las construcciones de piedra excavadas por García y Bellido. De las cabañas realizadas en materiales perecederos podemos decir pocas cosas, tal y como ya comentamos, al no conocer plantas completas de las estructuras constructivas a las que estaban asociados los barros. Los grosores de algunas de las muestras, no obstante, parecen más propios de una pared de una construcción que de elementos divisorios intermedios de los que no hay constancia hasta el momento ${ }^{17}$.

Para el presente artículo únicamente se ha estudiado una parte muy reducida del conjunto de pellas ${ }^{18}$. Aquellas que presentan restos de improntas más claros, junto con un número de ejemplares con unas marcas menos definidas pero que, como veremos, parecen remitir al mismo tipo de estructuras. Dentro de los ejemplares analizados también se ha incluido un fragmento de barro enlucido, para hacer una primera descripción de este tipo de elementos, como paso previo a otros estudios basados en los análisis de las piezas, cuestión que consideramos de vital importancia para seguir conociendo con mayor precisión la composición de estos enlucidos.

\section{Muestra PD-06/ 14 (Figura 4. C; 6 A)}

Fragmento de barro de forma irregular y con unas dimensiones de 129 x $35 \mathrm{~mm}$, con un grosor de $28 \mathrm{~mm}$. Presenta dos caras muy bien diferenciadas: por uno de sus lados, cuenta con una superficie muy regular de enlucido fino de escasos milímetros, que suponemos que era la que encontraba a la vista y que, por ello, contó con un acabado mucho más cuidado. Tanto sobre la superficie exterior como en la parte interna hay restos de las inclusiones que se mezclaron con el barro para dar una mayor consistencia

\footnotetext{
${ }^{17}$ Desconocemos los datos que llevan a algunos autores a afirmar que existen estancias divididas en el castro de Pendia, ya que ni en los restos del caserío excavado previamente ni en nuestras excavaciones se han localizado estructuras que sustenten tal afirmación (Ríos y García de Castro, 1998: 39).

${ }^{18}$ No se aportan dibujos convencionales de las piezas por la imposibilidad de acceso a los materiales arqueológicos depositados en el Museo Castro de Chao Samartín. Los requerimientos realizados por los titulares de la investigación han sido reiteradamente desatendidos por la autoridad municipal ante la pasividad de las instituciones con competencias en materia de patrimonio arqueológico.
}

al revoco. Entre ellos y a un nivel macroscópico se aprecian cuarzos y micas. Sí que parece existir una diferencia clara de tamaño entre las inclusiones utilizadas en la superficie externa, con respecto a las utilizadas en la parte interna, rasgo que permite suponer el empleo de distintos tipos de preparados para uno y otro sector.

En la parte interna es donde se localiza la única impronta de la pieza, que ha dejado un surco de $123 \mathrm{~mm}$ de longitud y una anchura de $30 \mathrm{~mm}$. Esta ligera concavi$\mathrm{dad}$, nos indica que el barro estuvo adherido a una vara de sección circular que suponemos que estaría formando parte de una estructura de madera que ejerce a modo de esqueleto de la construcción. Sobre esta marca no se entrecortan otros elementos de un posible entretejido. Sí que llama la atención la proximidad de la estructura de madera a la superficie exterior, cuestión que veremos que se repite en otros fragmentos.

\section{Muestra PD-06/52 (Figura 4. C; 6 B)}

Fragmento de barro de unas dimensiones de 119 × 61 $\mathrm{mm}$, con un grosor de $38 \mathrm{~mm}$ y una forma irregular pero con dos caras muy bien definidas. Por uno de sus lados se aprecia una superficie regular en la que se conserva lo que podrían ser los restos de los instrumentos utilizados para el alisado. Los desconchados de la cara externa del fragmento también indican que la masa principal del revoco y el acabado exterior tienen diferentes inclusiones y composición, utilizando una mayor cantidad de agua en la elaboración de este último. En ambas superficies predominan los esquistos de pizarra con algún cuarzo. En cuanto a las marcas de improntas éstas se pueden diferenciar dos marcas paralelas que dejan dos concavidades en el barro bastante claras y que hemos diferenciado como impronta 1 e impronta 2. La primera de ellas tiene mayor recorrido con una longitud de 77 $\mathrm{mm}$. , y una anchura de $24 \mathrm{~mm}$. La segunda tiene un ancho muy similar $(23 \mathrm{~mm}$.), pero es de menor longitud (60 mm.), y discurre paralela a la impronta 1. La impronta 2 se estrella contra un espacio en el que se reconoce con claridad una tercera marca (impronta 3), que ya es producto de un elemento en madera $u$ otro material que ha moldeado en el barro un ángulo recto. Mientras que las dos primeras improntas se conformaron al adherirse a varas de sección circular, la tercera impronta sólo puede ser producto de la colocación de un barrotillo de madera, de una jamba o incluso de otro tipo de elemento rectangular de $35 \times 12 \mathrm{~mm}$. La combinación de estas tres improntas nos está indicando un entramado de maderas que hemos tratado de reconstruir en la Figura 7. 
Desconocemos cuál sería la orientación original del fragmento, duda con la que también nos dejan el resto de casos estudiados. La poca distancia que existe entre la impronta 1 y la cara enlucida de la pared, también nos indica un revestimiento de escaso grosor.

\section{Muestra PD-06/60 (Figura 4. C; 6 C)}

Se trata de una pella de barro totalmente irregular de $77 \times$ $63 \mathrm{~mm}$, y el ejemplo de mayor grosor de los analizados en este estudio $(61 \mathrm{~mm})$. Únicamente se puede diferenciar una cara en la pieza, gracias a que cuenta con una impronta muy clara de $33 \times 29 \mathrm{~mm}$, que genera una profunda concavidad en la pelota de barro. Tal y como nos indican sus dimensiones, la impronta responde a una vara de sección circular de anchura muy similar a las descritas anteriormente. En la masa de barro también se pueden identificar varias inclusiones entre las que se reconocen esquistos de todos los tamaños, mezclados posiblemente con algún cuarzo. Se han encontrado otras piezas también con este aspecto de pella irregular, aunque sin restos de improntas en sus superficies.

\section{Muestra PD-06/63 (Figura 4. C; 6 D)}

Fragmento de barro de unas dimensiones de $77 \times 63$ $\mathrm{mm}$, con 45 milímetros de grosor. Al igual que el resto de los casos estudiados se identifican perfectamente dos superficies distintas. La primera de ellas, que podemos relacionar con el plano que estuvo en su momento a la vista cuenta con una superficie regularizada aunque de textura muy porosa y en la que se aprecia una extensa mancha azul claro. Esas irregularidades hacen que este ejemplo sea diferente a las muestras 14 y 52 estudiadas con anterioridad, donde los acabados son más gruesos y extensos, creando la sensación de enlucido o pátina exterior en el revoco que no se aprecia en este caso concreto. Tampoco podemos determinar a qué se debe esta diferencia; quizá distintos tipos de revocos, unos con acabado final y otros no, o bien un conservación diferente de las piezas.

En cuanto a las inclusiones en el anverso de la pieza son casi inapreciables distinguiéndose algunas micas. En cambio por el reverso las inclusiones son de mayor tamaño, con la presencia de esquistos de pizarra y algunas micas. Las irregularidades de esta cara son más evidentes, con una ligera concavidad bastante definida en la parte central que identificamos como la huella de una impronta de $77 \times 23 \mathrm{~mm}$; aunque esta muesca es menos evidente que los dos casos estudiados anteriormente, coincide con éstos en anchura.

\section{Muestra PD-06/77 (Figura 4. C; 6 E)}

Fragmento de revestimiento de forma irregular de $52 \times 47$ $\mathrm{mm}$ con una sección muy fina (de un grosor de $14 \mathrm{~mm}$ ), que permite la diferenciación de varias lechadas diferentes: sobre una masa principal de barro rojizo se aplicó una segunda capa de barro anaranjado de escasos milímetros. Por último, una película de barro de un naranja aún más claro sirve de enlucido final de la pared, que fue enjalbegada en alguno de sus tramos. Debido a que es un fragmento de pequeño tamaño no sabemos si se trata sólo de un motivo decorativo o el blanqueado era más extenso quizá agrupado por diferentes alturas en la pared. En otras piezas recuperadas en el entorno de C-3, también nos han aparecido elementos muy similares, asociados a estructuras de madera y a clavos, y toda la superficie exterior de algunos de esos fragmentos de barro presentaba enlucidos de color blanquecino (Fig. 3). El resto de la cara externa es totalmente uniforme (no presenta desconchados ni roturas) con algunas inclusiones de cuarzos. El reverso de la pieza está realizado sobre una masa de color rojizo que cuenta con inclusiones de esquistos de pizarra. Sobre la superficie dos marcas muy leves, una en la parte central (de $43 \times 20 \mathrm{~mm}$ ) y otra en uno de los extremos, podrían corresponderse con los restos de dos improntas de varas de madera.

\section{MATERIALES Y PROCESO CONSTRUCTIVO}

Tanto el barro como la madera fueron dos materiales fundamentales en buena parte de las etapas de la Prehistoria y la Protohistoria regional, peninsular y europea. Las primeras manifestaciones de estructuras erigidas con estos materiales se producen a lo largo de la Edad del Bronce peninsular, con diferencias muy llamativas en los tiempos de la investigación y en los restos constructivos entre unas y otras zonas de la península: en la zona levantina por ejemplo son bien conocidas desde hace décadas (Arribas, 1959), ya que se trata de yacimientos con características muy diferentes a los del Norte peninsular en los que la investigación pronto fijó su atención. En Asturias siempre se ha partido de la premisa de que este tipo de arquitecturas son las predominantes a lo largo de toda la Edad del Bronce (Maya, 1983: 23; Camino, 2005: 68), pero hasta hace pocos años no se han documentado arqueológicamente en sitios muy concretos ${ }^{19}$. Este panorama no es muy distinto al de otras regiones del NW peninsular aunque, como acabamos de apuntar, esta situación se deba

\footnotetext{
${ }^{19}$ Existen referencias a restos de estructuras muy diezmados bajo el caserío de la Edad del Hierro del Chao Samartín, que podrían vincularse con zonas de habitación contemporáneas del recinto de la acrópolis (Villa, 2007b: 29).
} 
más a una cuestión del ritmo de la investigación que a la carencia de yacimientos, tal y como demuestra la aparición reciente de zonas de habitación como la de Os Remedios (Moaña) que nos surten de información muy novedosa acerca de este período o incluso de fases anteriores (Bonilla y Fábregas, 2006: 271).

Las arquitecturas de la Edad del Bronce podrían tener similitudes con la arquitectura doméstica neolítica, pero carecemos en nuestra región de restos de este tipo que permitan una comparación sólida. A pesar de ello, siempre justificamos el desconocimiento de los poblados neolíticos por el carácter perecedero de sus edificaciones, aspecto en el que sí que hay semejanzas con buena parte de las arquitecturas de la Edad del Bronce o de la Edad del Hierro. Aunque la madera no esté siempre presente como material constructivo en los yacimientos, en buena parte de los casos hay que suponerle un papel relevante; los logros de la arquitectura megalítica serían impensables sin la participación de grandes maderos, del mismo modo que se empieza a reconsiderar el valor de algunas estructuras en este material ${ }^{20}$. En cuanto al barro aunque tampoco se haya documentado como elemento constructivo durante este período, es un material importante dentro del acervo tecnológico de las sociedades prehistóricas y forma parte de su cultura material. Así, no es extraño que en el valle del Navia se hayan recuperado vasijas prehistóricas (Sánchez, 2000: 245; de Blas, 2006: 240), que podrían ser una buena muestra del diálogo y de la experimentación con ese material.

Madera y barro tienen por tanto extensas biografías, con antecedentes muy remotos pero también con largas pervivencias que se dilatan hasta la actualidad como demuestra el uso que todavía tiene la madera o la recuperación de la construcción con tierra en proyectos arquitectónicos actuales (Maldonado, 2004: 252 y ss.) ${ }^{21}$.

Entrando ya de lleno en la importancia de estos materiales durante la Edad del Hierro, habría que comentar en primer lugar que a pesar de su abundancia y su temprano conocimiento, apenas si se han hecho estudios de detalle en nuestra zona. Y dentro de los recorridos generales que se han realizado, es probable que se puedan añadir un buen número de matizaciones si sigue aumen-

\footnotetext{
${ }^{20} \mathrm{La}$ madera es fundamental en la construcción de las cámaras pétreas de grandes ortostatos (De Blas, 1996: 31), pero hoy en día también se está reconsiderando la importancia de ciertas estructuras de carácter monumental levantadas en madera y contemporáneas a las estructuras megalíticas (Parker et alii, 2007: 628).

${ }^{21}$ El mantenimiento de ciertos conocimientos técnicos que están enraizados en el acervo constructivo de una comunidad humana y que procede de experimentaciones que siempre son mucho más antiguas, ya ha sido remarcado por otros autores para otras regiones peninsulares o europeas (Vela, 2005: 1062).
}

tando la información acerca de estos restos constructivos. La realización por tanto de estudios particulares de los yacimientos con este tipo de restos creemos que puede resultar muy interesante, no sólo para seguir avanzando en el estudio de panorámicas más amplias que van a necesitar del concurso de los estudios de yacimientos o de zonas específicas. Sino también para ayudar a resolver las diversidades constructivas que hayan pervivido en los yacimientos. Y partimos de una necesaria diversidad constructiva en vista de algunos ejemplos arquitectónicos actuales. Las cubiertas hechas con escoba por ejemplo, muestran la polivalencia de las soluciones arquitectónicas aunque estemos hablando de elementos que se caracterizan por una sencillez estructural, que puede estar cercana a la de las arquitecturas protohistóricas; al menos, siempre se han utilizado como continuo referente. En Asturias estas cubiertas tienen estructuras de soporte muy similares y utilizan un mismo material para cubrir los tejados, pero muestran un gran variedad de remates en la parte superior según el tipo de cubierta, o dependiendo del valle somedano en el que nos encontremos (Graña y López, 2007: 131).

En cuanto a los materiales en sí mismos y empezando por la madera, habría que decir que el modelo establecido para la arquitectura doméstica durante buena parte de la Edad del Hierro se ajusta a otra técnica muy bien conocida en la Protohistoria: el tejido, al que hay que suponer una antigüedad considerable. El principio estructural es muy similar a algunos entretejidos que han perdurado hasta la actualidad: una estructura de pilares verticales ejerce de urdimbre y sobre ella se teje una trama en horizontal con varas de las mismas dimensiones. Con esto ya tenemos el esqueleto del edificio, al que luego hay que proteger y buscar aislante para una cómoda habitación mediante la aplicación de capas de barro. Este modelo es de gran solidez y no insistiremos más en su descripción, pues ya se ha detallado anteriormente de forma bastante precisa para nuestra región (Camino, 1997: 65-66). Esta forma de construir también se adapta al marco general que se ha establecido para la II Edad del Hierro del NW: planta circular, techumbres vegetales y un diámetro de alrededor de $5 \mathrm{~m}$ por construcción (Ayán et alii, 2005-2006: 191), con distintos materiales usados según la zona, el yacimiento y la cronología que se analice.

La reconstrucción que se puede hacer de los tipos de impronta hallados en el castro de Pendia permite establecer una relación con este tipo de estructuras, aunque con una serie de matizaciones. Desde luego que las conclusiones que se emitan están sometidas al limitado corpus de muestras con las que se ha trabajado. 
Sí que resulta significativo que ningún ejemplar cuente con los restos de los dos elementos que forman el entretejido, la que ejerce de trama y la que hace de urdimbre. Únicamente se han documentado improntas de varas de madera en una dirección, tal y como ya le había ocurrido a X. Carballo Arceo en la excavación del castro de Cortegada (Carballo, según González, 2006-2007: 359), aspecto que en su momento llamó la atención al investigador gallego.

Los ejemplos de arqueología experimental desarrollados en Gran Bretaña en base a los registros arqueológicos, nos proporcionan más referencias de contraste: las varas verticales suelen ser siempre de estacas más gruesas: entre 75 y $80 \mathrm{~mm}$ de diámetro (Reynolds, 1988: 35), o incluso superiores a $90 \mathrm{~mm}$ (ibídem: 30). En algunas de los casas reconstruidas las varas verticales tienen entre 30 y $40 \mathrm{~mm}$, pero se corresponden con armazones que no soportarían el peso de una cubierta (ibidem: 36), por lo que fueron interpretadas como estructuras descubiertas.

Estos datos nos hacen pensar que las muestras procedentes de Pendia encajarían mejor como varas del entretejido horizontal; al menos parece más lógico relacionarlas con esta parte del tejido que con los postes verticales que forman la urdimbre de la pared, que vemos que suelen ser de mayor grosor. Por una cuestión estadística también es más probable que haya más restos de este tipo, ya que es más abundante el entramado de varas horizontales que los postes, que simplemente se encontrarían espaciados a distancias regulares. La considerable fragmentación de la pared en su momento de ruina produjo que en los fragmentos de barro analizados únicamente se hayan conservado restos de una vara, salvo en el caso de la muestra 52 que, aparte de las marcas del entramado horizontal que ejerce a modo de plemento de la pared, cuenta con huellas de un poste cuadrangular de cierto grosor, quizá la jamba de la puerta. Estos maderos también podrían ir recubiertos de barro, al ser una zona de tránsito continuo y muy expuesto a degradación.

Sobre la madera se aplicaría una gruesa capa de barro que ejercería como película protectora de la madera y que facilitaría el aislamiento completo de la estructura, lo que afectaría no sólo a cuestiones térmicas; también proporcionaría intimidad al espacio, al convertir un esqueleto de madera traslucido en una superficie opaca. Alguna de las superficies exteriores de esta capa de barro sufrieron distintos procesos de acabado, aunque a día de hoy resulta imposible determinar qué caras son las que reciben esos acabados. No sabemos si afectan a la interior, a la exterior o a ambas, ni tampoco en qué grado (sobre una zona concreta o sobre toda la pared). También desconocemos si es un fenómeno general a todas las cabañas o se ciñe sólo a unas construcciones concretas, en función de la finalidad de las mismas o del poder adquisitivo del que la construye, sea un individuo aislado o una parte de la comunidad. Hasta que no se puedan analizar las piezas tampoco se podrán precisar más sobre el tipo de inclusiones que presentan los barros, aunque la gama pudo ser variada como apuntan algunos autores: arena, paja, o incluso el pelo de animal pueden formar parte del aglomerado de barro (Audouze y Buchsenschutz, 1989: 54). A este repertorio se podrían añadir otras especies vegetales, como el brezo o el helecho que fueron documentados en la Campa Torres (Maya y Cuesta, 2001: 57) y que también encuentran sus paralelos en castros gallegos (Carballo, 2002: Lám. XVII). No sería extraño que se regulara la cantidad de inclusiones que deben acompañar al barro, cribando la arcilla o añadiéndole elementos. Tampoco podemos conocer con precisión si fueron necesarios procesos de macerado del barro, que siempre sería mucho más cómodo realizar sobre el mismo espacio en el que se iba a construir la casa, o en el entorno próximo. Como ya apuntamos, el entorno inmediato al poblado cuenta con buenas barreras, pero el aprovisionamiento de las arcillas en las cercanías no excluye la búsqueda en parajes más lejanos. En el caso de Pendia un entorno de kilómetro y medio de radio máximo parece un margen de aprovisionamiento más que suficiente, siempre como propuesta de trabajo inicial y en base a los datos con los que contamos actualmente.

Entre los acabados exteriores sí que podemos diferenciar dos tipos distintos de enlucidos: en primer lugar una serie de remates más sencillos de la cara vista que suponen la aplicación de una capa fina de preparado que tiene un color ligeramente más claro que el barro sobre el que se aplica (Audouze y Buchsenschutz, 1989: 54). Aunque de momento resulta imposible determinar la composición de esos acabados, a primera vista se asemeja a las lechadas empleadas en otras construcciones peninsulares del mismo período (Belarte, 1999-2000: 70), que simplemente se han logrado mediante el incremento de la cantidad de agua utilizada, lo que explicaría las escasas diferencias en su composición. Para fijar este preparado más acuoso se utilizaría un instrumento del que parece que se han conservado incisiones muy leves sobre alguna de las superficies exteriores. En segundo lugar tenemos un enlucido de mayor calidad y que supuso la aplicación de varias películas más claras sobre una masa principal de barro rojizo. Sobre las superficies más anaranjadas se extendía un enjalbegado de color blanquecino. No sabemos hasta qué 
punto la acción del propio incendio, o el tiempo de exposición de la pared al aire y al sol afectó sobre el color original. Algunas muestras estudiadas por Camino en la ría de Villaviciosa nos permiten saber que el color blancuzco de las piezas, puede deberse a la exposición al sol de unas texturas que en origen tenían color amarillo o anaranjado (Camino, 1995: 121). Aunque los ejemplos ${ }^{22}$ que estamos tratando son bastante sencillos, algunos edificios de la Edad del Hierro de la Meseta sí que manifiestan cierta complejidad en la composición y en los motivos decorativos (Celis, 1993: 105-106).

A pesar de que, visto desde la óptica actual, la aparente sencillez de los revestimientos podría llevar a equívocos, la información que contienen acerca de los procesos constructivos es considerable. La preparación de los dos materiales supuso seguramente una larga cadena de procesos de trabajo para estas comunidades. La madera tuvo que ser seleccionada previamente entre distintas especies, ya que debió ser un bien abundante y diverso; así al menos lo demuestran algunos estudios de la Edad del Hierro meseteña, que han documentado el vínculo existente entre estas comunidades y determinadas especies vegetales, ya sea en las inmediaciones del yacimiento o en su entorno próximo (Delibes et alii, 1995: 565). Siempre se seleccionan varas de similares dimensiones, con lo cual tenemos que suponer que existe un control sobre las propiedades mecánicas del esqueleto de madera: con la colocación de varas tejidas de determinado grosor la pared se sostiene. Todo ello presupone unos conocimientos técnicos fruto del acervo constructivo donde el componente experimental ha de ser también importante; esa práctica permite la introducción de novedades, la resolución de las posibles deficiencias del edificio, así como observar el comportamiento de la estructura ante las inclemencias meteorológicas como bien demuestran los ejemplos de arquitecturas primitivas (Rapoport, 1972: 140). Para que tengan esas propiedades es necesario cortar la vara de unas dimensiones concretas; esto facilitaría no sólo su colocación, sino también su transporte en grandes haces hasta el poblado. Sería lógico que las varas, antes de preparar los fardos para el transporte, ya fueran peladas en el sitio de la corta para eliminar todas las ramificaciones que resulten molestas para el transporte y la colocación. Si la madera era cortada dentro de unos plazos temporales concretos, podría existir una necesidad de almacenamiento de la misma hasta su colocación, ante lo cual la experiencia etnográfica

${ }^{22}$ El castro de la Campa Torres también presenta restos de este tipo de enlucidos (Maya y Cuesta, 2001: 57).
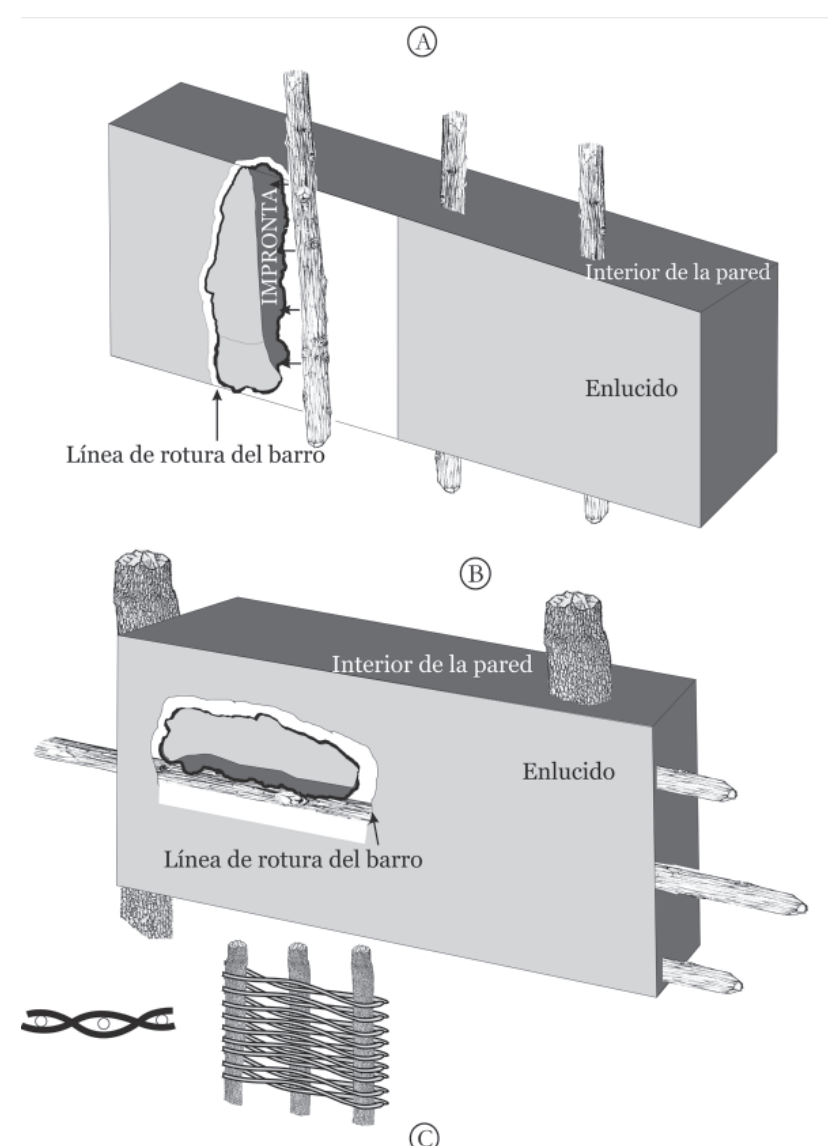

(C)

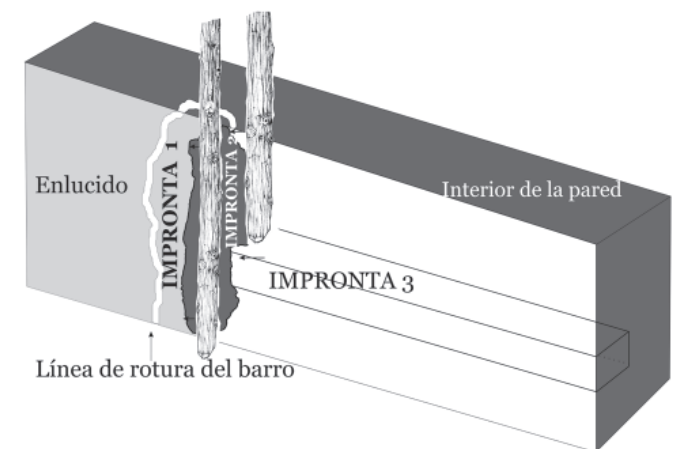

(D)

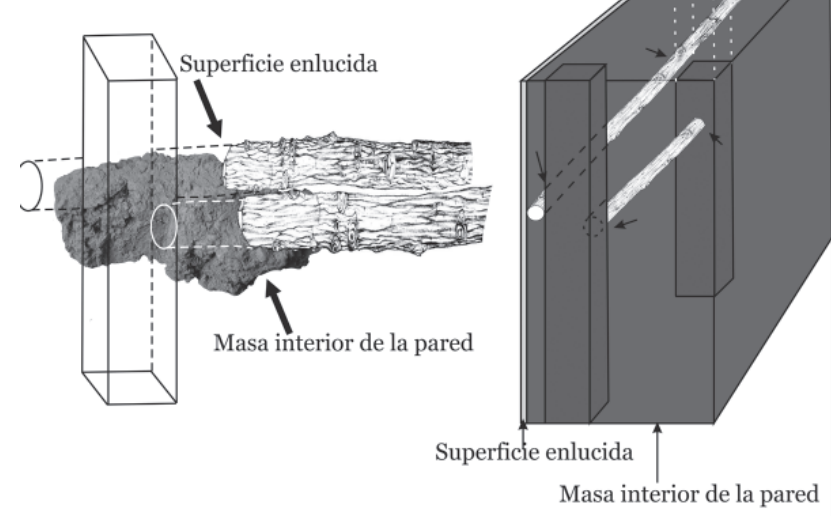

Fig. 7. Posibles interpretaciones de la posición de dos revocos. A. PD-06/ 14posición vertical. B. PD-06/ 14- Posición horizontal y posible estructura interior de la pared. C. PD-06/ 52. Posición vertical. D. PD-06/ 52- Posición horizontal 
nos indica que la inmersión de la madera en agua ya favorece su conservación. En la actualidad en Asturias se suele cortar la madera en relación con las fases lunares y en relación a los propios ciclos del árbol, conocimiento que seguramente viene de antiguo (Vitruvio, 2002: 121). La vareta de avellano por ejemplo, se suele cortar en el menguante de enero en la parte oriental de Asturias ${ }^{23}$, norma que no debe diferir mucho de la parte occidental ${ }^{24}$. La arquitectura popular es un buen ejemplo de la adaptación del avellano a las necesidades de la construcción, como demuestra su uso general en paredes exteriores de casas (Flores, 1987: 274), divisorias de construcciones auxiliares, etcétera. Es una madera flexible para el tejido, que es tenaz y duradera si se corta en los períodos adecuados y que hubo de ser abundante a lo largo de la Edad del Hierro como demuestra su aparición en yacimientos como la Campa Torres (Maya y Cuesta, 2001: 313-315), en el castro cántabro de los Baraones (Barril, 1995 según Torres, 2001-02: 149), o en los castros de Villaviciosa (Camino, 1997: 82), por poner varios ejemplos. De todos modos, hasta no contar con análisis específicos de los restos carbonizados, no podemos conocer con exactitud qué tipo de madera se empleó. Recordemos además que en aquellos lugares en los que se ha analizado con detenimiento los tipos de especies el resultado ha sido una gama muy variada de maderas disponibles durante la Edad del Hierro (Delibes et alii, 1995: 566). Muchas de ellas serían aptas para construir, aunque la localización de unos tipos determinados tampoco excluye inmediatamente el resto de especies; quizá haya que pensar en un uso concreto de la madera, según el edificio o según la parte del mismo que se estuviera construyendo. Todo ello en relación con las propiedades de la madera o de su disponibilidad. Algo semejante ocurre en la arquitectura popular asturiana, donde se prefiere el castaño (con revoco de barro) para los cierres de las viviendas, mientras que el avellano predomina en construcciones auxiliares o como elemento divisorio (Paredes y García, 2006: 68). En otros yacimientos de la época como Castrovite, también se emplearon varas de fresno en la construcción (Carballo, 1998, según González, 2006-2007: 360).

El trabajo en algunas zonas concretas, como las jambas de las puertas que seguramente serían también de

${ }^{23}$ Este dato de carácter etnográfico y algunos otros son resultado del trabajo sobre Cestería tradicional desarrollado por J. A. Fanjul, por D. Expósito y por el que suscribe, trabajo coordinado por J. López desde el Museo del Pueblo de Asturias. A todos ellos agradecemos su consentimiento para incluir los datos en este trabajo.

24 "No menguante de xineiro, corta el tou madeiro" decían en el concejo de San Martín de Oscos (García, 2002: 192). madera e irían incardinadas en el esqueleto estructural del edificio sería aún más complejo. La corta de maderos grandes, su transporte y preparación, requiere un utillaje más diverso que el simple podón de cortar y pelar varas, además de más horas de dedicación a la tarea, al menos en lo que respecta a la preparación de la pieza.

La aplicación de la capa de barro protectora sobre la madera también debería realizarse en épocas que favorecieran el secado correcto de la mezcla, para lo cual la climatología es un hecho determinante, mucho más en espacios tan húmedos y lluviosos como los de la Cornisa Cantábrica, que podrían alterar las propiedades mecánicas del barro. Una tarea más que añadir a los trabajos de mezcla del barro con otras inclusiones, sería el acarreo del producto final hasta el lugar de instalación de la casa. Tarea que aunque pueda parecer sencilla, no deja de tener cierta complejidad por el peso de la materia prima y por su conservación en buen estado hasta el momento de construcción. Resulta complicado calcular el barro necesario para las construcciones y quizá únicamente la arqueología experimental nos pueda proporcionar alguna referencia de interés. Reynolds ponderó la cantidad de barro precisa para revestir una construcción de madera (la casa Pimperne) obteniendo un resultado de varias toneladas de barro (1988: 38), cifra que aunque en primer lugar parezca excesiva, quizá no lo sea tanto si consideramos los más de diez metros de diámetro de la casa y la existencia de dos líneas de muro. Algunos autores mencionan la posibilidad de que se practicaran combustiones intencionadas y parciales del barro como método para alargar la vida de éste (González, 2006-07: 360). En el caso concreto de Pendia no contamos con datos para saber si este proceso se llevó a cabo.

Sí tenemos constancia de la existencia de fuegos vinculados a los restos constructivos del poblado, ya que ese proceso de cochura de los barros es el que posibilitó la pervivencia de estos materiales en la tierra. La larga perduración de las arquitecturas perecederas dentro de los poblados a lo largo de la Edad del Hierro e incluso hasta fechas más avanzadas (González, 2006-07: 350), junto con las cubiertas vegetales a las que siempre van asociadas (Camino, 1995: 121), facilitarían que se desencadenasen incendios dentro de los caseríos prerromanos. La prevención ante los incendios aún se constata en el siglo XIX en los pueblos que conservaban techumbres de materias vegetales, como el de El Val.le (Somiedo) y esa cautela obligó a crear regulaciones específicas en sus ordenanzas locales para evitar los incendios (Graña y López, 2007: 32). La ciudad de Oviedo reaccionó de modo muy semejante en 
época medieval, ante los riesgos de incendios dentro del recinto amurallado por el uso de madera en las cubiertas y en muros (o en algunos tramos de estos). Eso propiciará la sustitución de las viejas cubiertas, posiblemente de madera o paja (Argüello, 1999: 31), y la introducción de la teja en las cubiertas de los edificios de la ciudad a partir del siglo XIII. Estamos pues ante una preocupación latente, que es posible que también estuviera presente en estos poblados por lo que nos podríamos preguntar si la abundancia de incendios fue un acicate, al igual que en otros períodos históricos ya mencionados, para el empleo masivo de la piedra en la construcción ${ }^{25}$. El mayor número de atenciones que suelen precisar las construcciones de madera y barro pudo motivar también la preponderancia de unos materiales sobre otros en los ámbitos domésticos.

Pero la existencia de este peligro no implica que debamos hacer lecturas unidireccionales o una identificación inmediata a estos procesos constatados en otros períodos históricos. Mucho más si tenemos en cuenta que resulta imposible conocer con exactitud la naturaleza de esos fuegos: la existencia de una intensa relación con el fuego doméstico durante la Prehistoria, así como los inevitables fuegos ocasionados por causas naturales, no eluden la consideración de otro tipo de fuegos. Este tipo de enfoques creemos que pueden resultar sugerentes y se podrían trasladar a nuestro caso concreto, enriqueciendo las interpretaciones y estimulando también nuevas preguntas al registro. Y siguiendo con este tipo de interpretaciones también nos podríamos preguntar si son relevantes en el cambio entre perecedero y pétreo otros aspectos, como la faceta estética o el simbolismo que pudo tener la piedra como elemento constructivo (¿asociado a una mayor firmeza o a mayor seguridad?). Es curioso que en los pueblos actuales del occidente asturiano se dé un proceso cargado de connotaciones hacia el pasado inmediato, por el cual la gente vincula sus viejas casas de piedra con la escasez sufrida en determinadas épocas y prefiera casas nuevas hechas en cemento, soslayando cuestiones como que la piedra es mucho más valorada que el ladrillo en el mercado de la construcción ${ }^{26}$. Por tanto, nos preguntamos hasta qué punto la sustitución de las viejas construcciones de barro y madera por la piedra tiene que ver con procesos semejantes al descrito, extrapolados al contexto protohistórico.

${ }^{25}$ El incendio accidental de uno de los edificios reconstruidos en Numancia permitió constatar varios hechos: la rapidez del suceso, la desaparición de gran parte de las maderas de la techumbre y la nula afección sobre las paredes de piedra (Jimeno et alii, 2007: 235-253).

${ }^{26}$ Este fenómeno de la arquitectura tradicional "sucia», por el cual la gente identifica la vivienda tradicional con etapas de su pasado de cierta dureza ha sido ya bien constatado en Galicia por González Ruibal (1998: 175).
El cambio de materiales que se ha definido por algunos autores como monumentalización del espacio doméstico (Ayán et alii, 2005-2006: 187), todavía no resulta fácil de comprender. Quizá la conjunción de muchos factores sea la que nos pueda acercar más hacia las causas, sobre todo si tenemos en cuenta que en períodos anteriores la construcción con piedra ya había alcanzado gran desarrollo pero se limitaba únicamente a estructuras de carácter defensivo (murallas, torres), o de otros edificios relevantes para estas comunidades como las saunas u otras construcciones de cierta significación (Villa y Cabo, 2003: 149). Estos matices a la petrificación ya han sido expuestos, fundamentados en el desarrollo que en la Edad del Hierro adquieren las arquitecturas pétreas o las de los muros de aterrazamiento (De la Peña, 1988:22). Esto demuestra fehacientemente que el conocimiento de una determinada técnica constructiva no supone su aplicación a todo elemento construido (Rapoport, 1972: 39). Lo que desconocemos a día de hoy es el porqué de este fenómeno.

Sólo el estudio de detalle por yacimientos y por regiones podrá matizar este panorama en un futuro, sobre todo en vista de las grandes variaciones existentes según la comarca o la época que mantengamos en observación, cuestión que no sólo se puede apreciar en Galicia (González, 2006-07: 358-360), sino que también está presente en nuestra región como demuestra la comparación de las arquitecturas domésticas de la II Edad del Hierro de la parte oriental y la occidental.

Regresando de nuevo al castro de Pendia, quizá el mayor condicionante a la investigación de este tipo de restos en este yacimiento se encuentre en el propio devenir del caserío Sur: el núcleo con mayor concentración de edificios dentro del poblado. En este espacio se produjo un fenómeno muy frecuente en ocupaciones seculares sobre espacios tan concretos y delimitados como son los recintos intramuros: que las ocupaciones más antiguas se vean afectadas por las reformas posteriores. Casos como el de Torroso en Galicia (De la Peña,, 1992:16), Llagú (Berrocal-Rangel et alii, 2002: 126) o las intensas modificaciones documentadas en poblados como Moriyón durante la Edad del Hierro (Camino, 1997: 57), inspiraron a sus investigadores conclusiones muy similares. Será por tanto la intensidad de la ocupación sobre un mismo espacio la que dificulte realizar en Pendia un registro tan completo de la arquitectura de la Edad del Hierro como han propiciado, por ejemplo, algunos registros de los castros de la ría de Villaviciosa. La vinculación entre restos constructivos y las plantas de las construcciones, en los casos en los que se conserva y se puede recuperar, siempre nos permite contar 
con más información. Siempre y cuando el registro sea pulcro y la excavación lo suficientemente minuciosa, se puede llegar a recomponer la morfología de buena parte del edificio (si hay uno o dos pisos, los elementos presentes en cada uno de esos pisos, etcétera) (Morer et alii, 2000: 391). En este proceso de reconstrucción juegan un papel fundamental los materiales con los que se realiza la cubierta del edificio, al ser más problemático el rastreo de cubiertas hechas en exclusiva con materias vegetales, que acaban pereciendo dejando pocos rastros. Otro hándicap importante es que si los derrumbes de las estructuras de cubierta (viguería, tirantes, materiales de cubierta, etc.) no vienen asociados a barros con improntas es más difícil encuadrarlos como elementos constructivos. Sin embargo siempre hay casos que demuestran las posibilidades de un registro detallado; así, la excavación y estudio de los derrumbes de los materiales constructivos sobre los suelos de ocupación realizado en la Corona de Corporales demuestran la cantidad de información que se puede recuperar de cara a la reconstrucción de los tramos superiores del edificio (Sánchez Palencia y Fernández Posse, 1985: 92).En los poblados protohistóricos del este peninsular los tejados planos revocados con barro permiten rescatar en la excavación más elementos constructivos del viejo edificio (Morer et alii, 2000: 391). Bien es cierto que en otras ocasiones y a pesar de contar con los restos de los manteados de barro y de las estructuras negativas asociadas (hoyos de poste o zanjas), rehacer las plantas puede resultar de todos modos complejo, tal y como ocurre en el poblado de la II Edad del Hierro de Atxa (Gil, 1995: 195).

Estos condicionantes justifican que actualmente conozcamos muy pocos sitios en los que se conserven las distintas fases constructivas en una sucesión vertical de estructuras, a modo de palimpsesto en el que estudiar la evolución de la arquitectura castreña desde los elementos perecederos a las construcciones en piedra ${ }^{27}$.

\section{CONCLUSIONES}

La aparición de los restos de Cameixa (López, 1953: 77) abrió un nuevo capítulo en el estudio de las arquitecturas perecederas del NW de la península, ya que si bien se habían documentado restos similares en algunas excavaciones de principios de siglo XX éstos no habían tenido una interpretación tan nítida, asociándolos a sus posibles es-

\footnotetext{
${ }^{27}$ Las diez fases constructivas de la Primera Edad del Hierro del yacimiento de los Cuestos de la Estación, documentadas en una estratigrafía de 1,75 metros de potencia, podría ser uno de esos casos destacados de superposición de fases constructivas, aunque hay que decir que no presenta arquitectura pétrea (Celis, 1993: 97).
}

tructuras originales. Más de medio siglo después de esa publicación, los restos de arquitecturas perecederas siguen formando parte de los informes de excavación y de publicaciones diversas, y continúan usándose como testimonio de la existencia de fases antiguas dentro de los poblados fortificados, sin que en muchos casos se precise más acerca de su cronología. El proceder más común es vincular estos restos a fases de la Edad del Hierro que pueden estar o no avaladas por dataciones absolutas de $\mathrm{C}^{14}$. En Asturias, sólo a partir de la exhumación de espacios amplios de los caseríos castreños se pudieron documentar con claridad arquitecturas perecederas en las tres grandes demarcaciones de la región (central, occidental y oriental $)^{28}$. Aunque no tienen por qué registrarse en todos los yacimientos, debido a que están sometidos a la propia historia de cada lugar y a unas particulares condiciones para su conservación en la tierra, la nómina de yacimientos con este tipo de arquitecturas en nuestra región sigue ampliándose. Esta tendencia no parece que vaya a decaer, teniendo en cuenta la identificación casi generalizada de fases prerromanas en la gran mayoría de los yacimientos excavados, así como que, en muchas ocasiones, no es necesario que aparezcan los pallabarros. Los restos de estructuras de cimentación pueden ser un indicio suficiente para suponer el desarrollo de este tipo de arquitecturas.

A través de este estudio tratamos de describir los restos documentados en Pendia, y definir su contexto de localización con el fin de establecer si ocupan posiciones primarias o secundarias, información que nos resulta crucial y complementaria de los apartados descriptivos. Por último, hemos intentado dotarlos de asignación cronológica en relación con la secuencia estratigráfica en la que fueron recogidos. Con todo ello podemos suponer que las arquitecturas perecederas fueron habituales en algunas zonas del poblado de Pendia durante la Segunda Edad del Hierro; y esto a pesar que los hallazgos fueron recogidos en un espacio muy acotado sobre el que se fueron superponiendo distintas fases de ocupación a lo largo de, al menos, seis centurias. No podemos determinar hasta qué punto la sustitución de estas estructuras pudo ser progresiva o bien producto de una serie de restructuraciones más amplias y generales que se pueden apreciar en el urbanismo del sector meridional del castro. Además, el espacio no sólo era

\footnotetext{
${ }^{28}$ El proyecto de la Ría de Villaviciosa en la década de los 80 y los 90 y a partir de 1995 los trabajos del Plan Arqueológico del Navia-Eo son dos de los proyectos que no sólo han desarrollado excavaciones continuadas, sino que además han recuperado restos o estructuras constructivas de cierto interés vinculadas a un contexto estratigráfico muy explorado en distintos yacimientos y bien definido cronológicamente.
} 
reducido; también era bastante abrupto, lo que supuso que en algunos puntos se recurriese al desarrollo de terrazas, al menos en el último momento de ocupación. Se trata de plataformas que suelen requerir de estructuras de soporte o contención $^{29}$ y de una necesaria reorganización del poblado no sólo en horizontal; sino también en vertical. Ante la carencia de espacio y la necesidad de reformas o ampliaciones, buena parte de los restos constructivos de fases previas se convirtieron en parte integrante de los escombros con los que se pudo elevar la cota del terreno. Esto es lo que propicia la aparición o la conservación de los restos constructivos más antiguos en aquellos horizontes que se encuentran siempre por debajo del ya bien conocido caserío de piedra hoy visible. No es casual este fenómeno: en su gran mayoría las viejas estructuras, cuando se conservan, cumplen la función de soporte a nuevos edificios construidos en una cota superior. La conservación de las ruinas puede deberse a ese papel activo y necesario o bien a que sean elementos que perviven porque simplemente no entorpecen los nuevos proyectos constructivos. Parece ser éste el caso del espacio exterior de la construcción 12, donde se hallaron todos los restos estudiados en este trabajo. El hecho de encontrarnos ante los retazos del incendio y el derrumbe de una cabaña realizada con materiales perecederos pudo facilitar no sólo la aparición de los barros con improntas sino también de restos de maderas quemadas que fueron datadas por radiocarbono.

Pero, al margen de su contexto, los hallazgos de este tipo de arquitecturas, a pesar de que aparecen en muchas ocasiones en forma de escombro, siempre serán el resultado de una sucesión de pequeñas tareas sin las cuales no se pudo disponer de los materiales adecuados para construir una casa. La búsqueda, transporte y preparación del barro y de la madera dejan ver la necesaria organización de cada trabajo, posiblemente en tiempos muy determinados, así como un intenso conocimiento del entorno y de unos recursos perfectamente aprovechados.

No obstante hemos de ser cautos en las afirmaciones, ya que los restos de este tipo de materiales constructivos suelen ser, salvo casos excepcionales, una pequeña parte de las estructuras vigentes en su momento. Pero podemos concluir que los fragmentos considerados en este trabajo nos indican la existencia en Pendia de paredes muy similares a las encontradas en las cabañas de la Edad del Hierro de la ría de Villaviciosa, formadas por postes verticales entre los que se entretejen varas más finas de similares groso-

\footnotetext{
${ }^{29}$ En muchos casos las propias paredes de las construcciones ejercieron ese papel, tal y como ocurre en C-2, C-6 y en C-9.
}

res. Todo ello revestido con barro sin que de momento se pueda precisar el tipo de maderas utilizadas. Los acabados del barro, que tendrían una función protectora de la pared, también pueden tener un componente estético viendo algunos remates en blanco u otros colores, de elaboración más cuidada. De momento no podemos dar más datos acerca de su extensión sobre la pared o de si su presencia es general en todos los paños o se limita a paredes concretas. El grosor de algunas piezas es estimable y estarían formando parte del núcleo interior de la pared, sin que muchas de ellas conserven restos de improntas. Por último, hemos de suponer que el barro proceda del entorno próximo al poblado, información que podrá verse corroborada si se desarrollan análisis cruzados de canteras y muestras.

AGRADECIMIENTOS: Miguel Ángel de Blas, Ángel Villa, Esperanza Martín, Jorge Camino, Alfonso Menéndez, José Antonio Fanjul, Sofía Díaz y a Juaco López por su ayuda a la hora de hacer este artículo. Miguel Busto, Carmen Álvarez, Diego Díaz, Marta Ledo, Aurora Rodríguez, Teresa Suarez, Javier Vigil y David Expósito colaboraron en las campañas de excavación. El geólogo Roi Sampedro revisó la parte de geología y materias primas. Este y otros trabajos son posibles gracias a todo el equipo de la Cuenca del Navia-Eo, por eso nuestro agradecimiento y nuestra deuda.

\section{Bibliografía}

Aboal Fernández, R., Cancela Cereijo, C., Castro Hierro, V. y Rodríguez Martínez, R. (2009): «Intervención avaliativa para a recuperación patrimonial do castro de Sete Fontes, Barro (Pontevedra)», Actuacións arqueolóxicas. Ano 2007, 27-29.

Acuña Castroviejo, F. y Meijide Cameselle, G. (1991): «Castro de A Graña (Toques, A Coruña)», Arqueoloxia. Informes 2. Campaña de 1988, 51-54.

- (1995): «Escavación arqueológica no Castro de A Graña (Toques, A Coruña)», Arqueoloxia. Informes 3. Campaña de 1989, 23-24.

Álvarez González, Y. y López González, L. F. (2000): «La secuencia cultural del asentamiento de Laias: evolución espacial y funcional de un poblado", Actas del III Congreso de Arqueología Peninsular. Proto-história da Península Ibérica. Vila Real, 523-532.

Álvarez González, Y., López González, L. F. y López Marcos, M. A. (2006): «La secuencia cultural en el castro de Vilela", Cuadernos de Estudios Galegos, LIII, no119, 7-29.

Álvarez Merayo, I. A. (2009): "Sondaxes arqueolóxicas no castro da Ourela, S. Xurxo-Augas Santas, Palas de Rei (Lugo)", Actuacions arqueoloxicas. Ano 2007, 58-59.

- (2010): «Sondaxes arqueolóxicas no xacemento castrexo de Monforte de Lemos (Lugo)", Actuacions arqueoloxicas. Ano 2008, 63-64.

Álvarez Nuñez, A. (1986): Castro de Penalba. Campaña de 1983, Arqueoloxía/ Memorias, 4.

Argüello Menéndez, J. J. (1999): "Materiales de construcción de les cases asturianes na Edá Media», en Asturies: Memoria encesa d' un país, 8. 28-48.

Arias Vilas, F. (1979): «El castro de Penarrubia y la novedad de su datación por C-14", XV Congreso Nacional de Arqueología, Lugo 1977, Zaragoza, 613-622. - (1991): «Castro de Viladonga (Castro de Rei, Lugo)», Arqueoloxia. Informes 2. Campaña de 1988, 71-75. 
- (1995): «Escavación arqueolóxica e limpieza no Castro de Viladonga (Castro de Rei, Lugo)", Arqueoloxia. Informes 3. Campaña de 1989, 25-28.

Arribas Palau, A. (1959): «El urbanismo peninsular durante el Bronce primitivo", Zephyrus, X, 81-128.

Audouze, F. y Buchsenschutz, O. (1989): Villes, villages et campagnes de l'Europe celtique : du début IIe millénaire à la fin du Ie siècle avant J.C.

Ayán Vila, X. M, Otero Vilariño, C. y González Ruibal, A. (2007): «Sondaxes arqueolóxicas no Castro de Castrolandín (Cuntis, Pontevedra): campaña de 2004», El Museo de Pontevedra, no 61, 11-62.

Ayán Vila, X. M., Pope, R. y Alberro, M. (2005-2006): «Una Edad del Hierro redonda: la cabaña circular en los castros del NW de la Península Ibérica», Kalathos, 24-25, 177-217.

Ayán Vila, X. M. y Franco Fernández, M. A. (2010): «Escavación no castro pequeno do Neixón, Boiro (A Coruña)», Actuacions arqueoloxicas. Ano 2008.46-48.

Bartolomé Abraira, R. (2008): «Primeiras valoracións da intervención realizada na Agra dos Castros, Marcelle (Lugo)», Boletín da Asociación de Amigos do Museo do Castro de Viladonga, 18, 28-33.

Belarte Franco, M. C. (1999-2000): «Sobre el uso del barro en la protohistoria del Bajo Aragón: estudio de materiales conservados en el Museo de CataluñaBarcelona», Kalathos, 18-19, 65-93.

Bellmunt, O. y Canella, F. (1900): Asturias. Gijón.

Berrocal-Rangel, L., Martínez Seco, P. y Ruiz Triviño, C. (2002): El castiellu de Llagú (Latores, Oviedo). Un castro astur en los origenes de Oviedo. Biblioteca Archaelógica Hispana, 13. Madrid.

Blas Cortina, M. A. de. (1996): «Arquitectura prehistórica», El arte en Asturias a través de sus obras, Oviedo, 21-36.

- (2006): «La arquitectura como fin de un proceso: una revisión de la naturaleza de los túmulos prehistóricos sin cámaras convencionales en Asturias", $Z e$ phyrus, 59, 233-255.

Bonet Rosado, H. (2006): «Tres modelos de arquitectura defensiva y protección del territorio. Edeta, Kelin y la Bastida de les Alcuses", Arquitectura defensiva. La protección de la población y del territorio en época ibérica (Oliver Foix, A. coord.), 13-46.

Bonilla, A., Vila, M. C. y Fábregas, R. (2006): «Nuevas perspectivas sobre el espacio doméstico en la prehistoria reciente del no: el poblado de Os Remedios (Moaña, Pontevedra)", Zephyrus, 59, 257-273.

Calo Lourido, F. y Soeiro, T. (1986): Castro de Baroña. Campañas de 1980/84. Arqueoloxia/Memorias, 6, Santiago de Compostela.

Cano Pan, J. A. y Gómez Filgueiras de Brage, F. (2010): «La Paleometalurgia del Poblado de Punta de Muros (Arteixo, A Coruña) en el contexto de la transición Bronce Final - Primera Edad del Hierro", Cuaternario y Arqueología. Homenaje a Franscico Giles Pacheco, Cadiz, 253-261.

Camino Mayor, J. (1995): «Excavaciones arqueológicas en castros de la ría de Villaviciosa: apuntes para una sistematización de la Edad del Hierro", Excavaciones arqueológicas en Asturias 1991-1994, 3, 117-126.

- (1997): «Excavaciones en castros de la Ría de Villaviciosa», Estudios del poblamiento prerromano en la ría de Villaviciosa, Cuadernos Cubera, 9, 43-86.

- (2005): «Prehistoria e historia antigua. El primer milenio antes de Cristo. La cultura prerromana» en Historia de Asturias. Fernández Pérez, A. y Friera Suárez, F. (coord.), 74-103.

Carballo Arceo, L. X. (2002): A cultura castrexa na bacia media do río Ulla. Concello de Lalín.

Carreño Gascón, C. (1991): «Castro de Saceda (Cualedro, Orense)», Arqueoloxia. Informes 2. Campaña de 1988, 59-61.

Carrocera Fernández, E. y Jordá Pardo, J. (1986-87): «Medio geológico y hábitat en los poblados fortificados del occidente asturiano», Zephyrus, 3940, 215-229.

Carrocera Fernández, E. (1990): «"El castro de San Isidro: informe de las excavaciones arqueológicas 1986", en Excavaciones arqueológicas en Asturias, 1, 1983-86, 157-162.

Celis Sánchez, J. (1993): «La secuencia del poblado de la Primera Edad del Hierro de «los Cuestos de la Estación», Benavente (Zamora)», en Arqueología vaccea: estudios sobre el mundo prerromano en la cuenca media del Duero, Romero Carnicero, F., Sanz Mínguez, C. y Escudero Navarro, Z. (eds.), Valladolid, 93-132.
Collantes, A. (1855): Diccionario de agricultura práctica y economía rural. T. II y VII, Madrid.

Criado Boado, F. (Dir.) (1991): Arqueología del paisaje. El área Bocelos-Furelos entre los tiempo paleolíticos y medievales (campañas de 1987, 1988 y 1989), Arqueoloxía/investigación, 6, Santiago de Compostela.

Chapa Brunet, T. y Mayoral Herrera, V. (2007): Arqueología del trabajo. El ciclo de vida de un poblado ibérico, Madrid.

Delibes, G, Romero, F., Escudero, Z., Sanz, C., San Miguel, L. C., Mariscal, B., Cubero, C., Uzquiano, P., Morales, A., Liseau, C. y Calonge, G. (1995): «El medio ambiente durante el primer milenio a. C. en el valle medio del Duero. Consideraciones finales", Arqueología y medio ambiente. El primer milenio a. C. en el Duero Medio. Delibes, Romero y Morales (Eds.), Escudero Navarro, Z. (Coord.), Valladolid, 543-582.

De la Peña Santos, A. (1992): Castro de Torroso (Mos, Pontevedra): sintesis de las memorias de las campañas de excavaciones 1984-1990, en Arqueoloxía/Memorias, 11, Santiago de Compostela.

De Llano y Roza de Ampudia, A. (1919): El libro de Caravia. Oviedo.

Fanjul Mosteirín, J. A., Villa Valdés, A. y Menéndez Granda, A. (2009): «El castro de Cabo Blanco, Valdepares (El Franco): informe sobre los trabajos de acondicionamiento y exploración arqueológica (2004-2007)», en Excavaciones Arqueológicas en Asturias 6 (2003-2006), 255-264.

Fanjul Peraza, A. (2007): «Excavaciones en el castro de la Garba (Teverga), Asturias. Primeros trazos arqueológicos del poblamiento castreño en la alta montaña", Estudios varios de arqueología castreña. A propósito de las excavaciones en los castros de Teverga (Asturias), Fanjul Peraza, A. (coord.), Santander, 4975 .

Fernández Malde, A. (2008): «Proxecto de posta en valor do castro das Travesas, Carral (A Coruña)», Actuacions arqueoloxicas. Ano 2006, 46.

Fernández Ochoa, C. y Villa Valdés, A. (2004): «El castro de Coaña antes y después de García y Bellido: claroscuros en el tránsito de la erudición al discurso científico", Antonio García y Bellido. Miscelánea. Serie Varia 5, Blanquez Pérez falta y Pérez Ruiz, M. (Ed. Cient.), Madrid, 129-141.

Fernández Pintos, M. ${ }^{a}$ P. (2008): «Sondaxes arqueolóxicas valorativas e actuacións complementarias en Castriño de Bendoiro, Lalín (Pontevedra)», Actuacions arqueoloxicas. Ano 2006, 181-182.

Fichtl, S. (2005): La ville celtique: (les «oppida» de 150 av. J.-C. à 15 ap. J.-C.).

Flores, C. (1987): Arquitectura popular española, T. II. Regiones del Norte y Noroeste peninsular, Madrid.

García Martínez, A (1929): Prehistoria del occidente de Asturias, inédito.

García Martínez, A. (2002): La casa tradicional de San Martín de Oscos, Gijón.

García Rollán, M. (1971): «Memoria de la excavación arqueológica de Castromao», Archivo Español de Arqueología, 44, 175-211.

García y Bellido, A. (1942): «El castro de Pendia», Archivo Español de Arqueología XV, 48, 288-307.

- (1942b): «El castro de Coaña (Asturias); nuevas aportaciones», Archivo Español de Arqueología, 48, 216-244.

Gil Zubillaga, E. (1995): Atxa. Memoria de las excavaciones arqueológicas 19821988. Memorias de yacimientos alaveses, 1, Vitoria.

González Ruibal, A. (1998):» Etnoarqueología de los abandonos en Galicia. El papel de la cultura material en una sociedad agraria en crisis», Complutum, 9, 167-191.

- (2004):»Alen dos castros: o poboado da idade do ferro de Pena Redonda (Ponte Caldelas, Pontevedra), El museo de Pontevedra, LVIII, 11-63.

- (2006-2007): Galaicos: Poder y Comunidad en el Noroeste de la Peninsula Ibérica (1200 a.C.- 50 d.C.), tomos I y II. Brigantium, 18 y 19.

Graña, A. y López Álvarez, J. (2007): Los teitos en Asturias. Un estudio sobre la arquitectura con cubierta vegetal. Gijón.

Heredero García, R. (1995): «Casas circulares y rectangulares de época vaccea en el yacimiento del Cerro del Castillo (Montealegre)", Arqueología vaccea: estudios sobre el mundo prerromano en la cuenca media del Duero, Romero Carnicero, F., Sanz Mínguez, C. y Escudero Navarro, Z. (eds.), Valladolid, 279-302.

Hidalgo Cuñarro, J. M. (1984): «Castro de Troña (As Pías), Arqueología 83, $\mathrm{n}^{\circ} 240.232$.

Hidalgo Cuñarro, J.M. y Rodríguez Puentes, E. (1987): Castro de Fozara. Campaña de 1984 en Arqueoloxia/Memorias, 9, Santiago de Compostela. 
Jimeno, A., Martínez, J. P., Chaín, A. y Algarra, H. (2007): «Incendio en Numancia. Una experimentación no pensada», Arqueología experimental en la Península Ibérica. Investigación, didáctica y patrimonio, Santander, 235-253.

Jordá Cerdá, F. (1964): «Actividades arqueológicas en el distrito universitario de Oviedo", en Noticiario Arqueológico Hispánico. Cuadernos 1-3, 1962, 368371.

Lois Ladra, X. L. (2010): «Sondaxes arqueolóxicas no castro de Chandebrito, Nigrán (Pontevedra)", Actuacions arqueoloxicas. Ano 2008, 35-36.

López Cuevillas, F. (1953): «Castro de Cameixa (campaña de 1944)», Noticiario Arqueológico Hispánico, Tomo I, 1952, 75-81.

López García, J.C. (2008): «Escavación en área no xacemento de San Tomé de Nogueira, Meis (Pontevedra)", Actuacions arqueoloxicas. Ano 2006, 185186.

López González, L. F. (2008): «Posta en valor de Castromaior para fomento do turismo cultural no Camino de Santiago, Portomarín (Lugo)", Actuacions arqueoloxicas. Ano 2006, 33-34.

Luzón J. M. ${ }^{a}$ y Sánchez Palencia, F. J. (1980): El Caurel, Excavaciones arqueológicas en España, 110.

Maldonado Ramos, L. (2004): «El papel liberador de la nueva construcción con tierra en la evolución de la arquitectura actual», Actas del II Seminario Iberoamericano de construcción con tierra (Maldonado, L., Rivera, D. y Vela, F. eds.), 251-256.

Maluquer de Motes, J. (1963): «La cultura material de los pueblos del NW peninsular», en Historia de España (Menéndez Pidal, dir.). Tomo I, España Prerromana, vol. III, Etnología de los pueblos de Hispania, Madrid.

Marcos Vallaure, A. (1973): Las series del paleozoico inferior y la estructura herciniana del Occidente de Asturias (NW de España), Trabajos de Geología, 6.

Maya González, J. L. et alii (1983): Indigenismo y romanización en el conventus asturum, Gijón.

Maya González, J. L. (1988): La cultura material de los castros asturianos, Estudios de la Antigüedad 4/5, Barcelona.

Maya González, J. L. y Cuesta Toribio, F. (2001): El castro de la Campa Torres: el periodo prerromano, serie Patrimonio, 6, Gijón.

Meijide Cameselle, G. (2011): «Novas perspectivas sobre a cultura castrexa na provincia de Lugo. As achegas do castro de Formigueiros (Samos)", $A$ prehistoria en Lugo a través das descobertas recentes. Dopico Cainzos, D. y Villanueva Acuña, M. (Eds.).

Morer, J., Carme Belarte, M., Sanmartí, J. y Santacana, J. (2000): «Experimentación en arquitectura protohistórica: el Laboratorio de Arqueología Experimental de El Vendrell (Baix Penedés, Tarragona)», Protohistoria da Peninsula Ibérica. Vol. V. Actas do $3^{\circ}$ Congreso de Arqueología Peninsular (ADECAP), 389399.

Orero Grandal. L. (1988): Castro "Coto do Mosteiro». Campañas de 1984-85, Arqueoloxía/Memorias, 10, Santiago de Compostela.

Paredes, A. y García Martínez, A. (2006): La casa tradicional asturiana, Oviedo.

Parga Castro, A. (2008): «Sondaxes arqueológicos valorativas no castro de Cruceiro da Coruña, Santiago de Compostela", Actuaciones arqueológicas en Galicia 2006, 125-126.

Parker Pearson, M., Cleal, R., Marshall, P., Needham, S., Pollard, J., Richards, C., Ruggles, C., Sheridan, A., Thomas, J., Tilley, C., Welham, K., Chamberlain, A., Chenery, C., Evans, J., Knüsel, C., Linford, N., Martin, L., Montgomery, J., Payne, A. \& Richards, M. (2007): «The age of Stonehenge», Antiquity, 81, no 313, 617-639.

Ramil González, E. (1989): «Castros do concello de Ortigueira (Ortigueira, A Coruña)", Arqueoloxía/Informes, 1, 58-63.

Rapoport, A. (1972): Vivienda y cultura, Barcelona.
Reynolds, P. J. (1988): Arqueología experimental: una perspectiva de futur; traducción de M. Pilar Espadaler.

Ríos, S. y García de Castro, C. (1998): Asturias castreña, Gijón.

Rodríguez Colmenero, A. (1976): «Excavaciones arqueológicas en el castro de Novas (Orense)», Noticiario Arqueológico Hispánico, 4. 549-584.

Rodríguez del Cueto, F. y Villa Valdés, A. (2009): «Excavaciones arqueológicas en el castro de Pendia (Boal), Excavaciones Arqueológicas en Asturias 6 (20032006), Oviedo, 159-170.

Romero Masiá, A. M.a (1976): El hábitat castreño. Asentamientos y arquitectura de los castros del noroeste peninsular. Santiago de Compostela.

Sánchez Hidalgo, E. (2000): «Túmulo I del conjunto tumular de La Xorenga, El Canadeiro (Xestoselo, Grandas de Salime, Asturias). Mundo funerario neolítico en el occidente asturiano", Actas del III Congreso de Arqueología Peninsular. Neolitizaçao e megalitismo da Península Ibérica. Vila Real, 239-254.

Sánchez Palencia, F. J. y Fernández-Posse, M. ${ }^{a}$ D. (1985): La Corona y el castro de Corporales I. Truchas (León). Campañas de 1978 a 1981, Excavaciones arqueológicas en España, 141, Madrid.

Suárez Otero, J. y Fariña Busto, F. (1990): «A Lanzada (Sanxenxo, Pontevedra), definición e interpretación de un yacimiento castreño atípico. Apuntes para un estudio de los intercambios protohistóricos en la costa Atlántica peninsular", Madrider Mitteilunguen, 30, 309-337.

Tomás Botella, V. (2008): «Escavación arqueolóxica no castro de Viladonga, Castro de Rei (Lugo)», Actuacions arqueoloxicas. Ano 2006, 39-40.

Torres Martínez, J. F. (2001-02): «Silvicultura, recursos forestales y paleoambiente en la economía de la protohistoria final del norte peninsular", Kalathos, 20 21, 139-158.

Vela Cossío, F. (2005): «Materiales, técnicas y sistemas de construcción en la arquitectura celtibérica de la primera Edad del Hierro", Actas del Cuarto Congreso Nacional de Historia de la Construcción, Cádiz, 1051-1064.

Vigo, A. (2006): "Castro de Zoñán (Mondoñedo, Lugo). Campaña 2005. Avance de resultados», Gallaecia, 25, 65-81.

Villa Valdés, A. (1999). "Plan Arqueológico Director de la Cuenca del Navia», en Excavaciones Arqueológicas en Asturias 4 (1995-1998), Oviedo, 205-211.

Villa Valdés, A. (2000): «Saunas castreñas en Asturias», II Coloquio Internacional sobre termas romanas en el Occidente del Imperio, Gijón, 97-114.

Villa Valdés, A. y Cabo Pérez, L. (2003): «Depósito funerario y recinto fortificado de la Edad del Bronce en el castro del Chao Samartín: argumentos para su datación», Trabajos de Prehistoria, 60, no 2, 143-151.

Villa Valdés, A. (2004): «Poblados y recintos fortificados en tierras de Los Oscos», Campo del Tablado I. Sociedad Asturgalaica de amigos del País. Castropol, 85-95.

Villa Valdés, A. (2007). «Saunas castreñas en poblados fortificados de Asturias y Galicia», Pedra Formosa, Vila Nova de Famaliçao, 66-92.

Villa Valdés, A. (2007b): «Mil años de poblados fortificados en Asturias (siglos IX a.C.-II d.C.)", Astures y romanos: nuevas perspectivas. J. A. FernándezTresguerres (Coord.), Oviedo, 27-60.

Villa Valdés, A., Menéndez Granda, A. y Fanjul Mosteirín, J. A. (2007): «Excavaciones arqueológicas en el poblado forticado de Os Castros, en Taramundi», Excavaciones arqueológicas en Asturias 5 (1999-2002), 267-275.

Villa Valdés, A. (2008):»La arquitectura doméstica en los castros prerromanos", $\mathrm{La}$ Prehistoria en Asturias. Un legado artístico único en el mundo, Oviedo. 721-730.

Villa Valdés, A. y Menéndez Granda, A. (2009):»Estudio cronoestratigráfico de las murallas del castro de San Chuis, en San Martín de Beduledo (Allande, Asturias)", BIDEA LXIII, 173-174, 159-179.

Vitruvio Polión, M. L. (2002): Los diez libros de arquitectura, (3a reimpresión), Madrid. 